\title{
Local vibration mode pairs for damage identification in axisymmetric tubular structures
}

\author{
Obukho E. Esu' ${ }^{1}$, Ying Wang ${ }^{1,2}$, Marios K. Chryssanthopoulos ${ }^{1}$ \\ 1. Department of Civil and Environmental Engineering, University of Surrey, Guildford, Surrey, GU2 \\ 7XH, United Kingdom \\ 2. School of Civil and Environmental Engineering, Harbin Institute of Technology (Shenzhen), \\ Guangdong, 518055, China
}

\begin{abstract}
Tubular structures are widely used in infrastructure, especially for pipes and marine installations. Corrosion is a key damage type for these structures, and if undetected may cause structural deficiency or even collapse. This paper investigates the effects of localised corrosion on the vibration properties of axisymmetric tubular structures and proposes a novel baseline-free damage identification method to overcome the fact that the difference between undamaged and damaged properties is usually small and contaminated by noise. The proposed vibration-based method exploits the phenomenon of repeated mode pairs which is peculiar to axisymmetric tubular structures with non-axisymmetric damage. Unlike intact tubular structures, it is found that each vibration mode of a locally damaged tubular structure comprises of two components: active and passive. The active component is sensitive to the local damage and can be used to infer damage existence while the passive component is retentive of the undamaged pipe's properties. Therefore, the passive component of a damaged pipe' $^{\prime}$ s local vibration mode pair (LVMP) can be used to predict its baseline (undamaged) modal properties, which in this research was achieved within a margin of $\pm 2 \%$, whereas the active component confirms damage existence. The work also establishes the criteria for validation of LVMPs through experimental tests involving various corrosion scenarios ranging from longitudinal strips to throughthickness pits. Based on the obtained results, it is proposed that the properties of LVMPs can be linked to corrosion-like local damage in axisymmetric tubular structures, underpinning a new damage detection and identification approach.
\end{abstract}

\section{Keywords}

Corrosion Detection in Pipes; Vibration-based Damage Identification; Structural Health Monitoring; Modal Analysis; Repeated Modes; Split Modes. 
Table 1 Nomenclature

\begin{tabular}{ll}
\hline$a$ & Sub-case suffix corresponding to $\gamma_{\text {cor }}=90$ degrees \\
$b$ & Sub-case suffix corresponding to $\gamma_{\text {cor }}=45$ degrees \\
$c$ & Sub-case suffix corresponding to $\gamma_{\text {cor }}=0$ degrees \\
$f$ & Modal frequency \\
$C S A_{c o r}$ & Percentage of cross-sectional area lost to corrosion \\
$f_{\max }$ & Maximum expected theoretical frequency \\
$f_{S}$ & Sampling frequency \\
$K_{\Delta F}$ & Vector of LVMP components frequency deviations ranked from lowest to highest \\
$L_{p i p e}$ & Length of pipe \\
$M_{\text {cor }}$ & Mid-point of corrosion damage along pipe length \\
$O D_{p i p e}$ & Outside diameter of pipe \\
$R_{\Delta F}$ & Range of LVMP components frequency deviation \\
$T_{\text {cor }}$ & Thickness of pipe lost to corrosion \\
$V O L_{c o r}$ & Percentage of pipe volume lost to corrosion \\
$W T_{p i p e}$ & Wall thickness of pipe \\
$\alpha_{\text {cor }}$ & Angle subtended by corrosion pit \\
$\Delta f$ & Baseline frequency deviation \\
$\Delta F$ & Difference between frequencies of LVMP components \\
$\Phi$ & Modeshape vector \\
$\gamma,\left(\gamma_{c o r}\right)$ & Angle between excitation axis and imaginary axis through damage (corrosion) \\
$A$ & centroid and pipe centre \\
$P$ & Subscript corresponding to the Active component of LVMP modal property \\
\hline
\end{tabular}

\section{Introduction}

The need for a simple yet, effective method for non-destructively identifying corrosion in tubular structures such as pipes, circular hollow sections etc. would be of benefit to many infrastructure sectors, since undetected corrosion can lead to unexpected structural collapse with severe consequences. For example, in 2013, the estimated cost of corrosion to the world economy was circa USD 2.5 trillion [1] and led to numerous failures ranging from pipeline explosion to aircraft damage [2]. Whilst there exists various means of nondestructively detecting corrosion in pipes ranging from guided wave [3] to magnetic flux leakage [4] methods, vibration-based techniques are advantageous given their relatively low cost, simplicity and robust theoretical background [5] - [8].

In general, damage detection in tubular cross-sections is not as widely investigated as in other types of structures. Some of the traditional vibration-based damage indicators such as modeshape curvature [9] and modal strain energy [10] were initially tested on non-tubular cross-sections, whereas other methods [11] relate to plated structures. One of the challenges with the application of vibration-based methods to tubular structures from an operational perspective is the presence of the transmission fluid which may perturb the structure' s modal properties. Nonetheless, some studies date back to the early 20th century according to [12] which reviewed various works on the subject up to the 
1990 's. The reviewed works were mainly theoretical and were not necessarily aimed at damage detection but focussed on providing a better understanding of the dynamics of pipes especially with fluids flowing within. One of the pioneering attempts at vibrationbased damage identification in a pipe with fluid is presented in [13] where the location and size of cracks were predicted based on frequency measurements. A numerical method developed in [14] was used to identify a single open crack in a straight pipe containing fluid under pressure from the first two vibration frequencies of the pipe. Similarly, [15] employs changes in natural frequencies to predict the location and size of cracks in a pipe while [16] presents a numerical study of the dynamic behavior of cracked simply supported pipes conveying fluid with moving mass. Other works focused on crack detection in pipes include [17], where a framework for detecting multiple progressive cracks in steel pipes based on vibration responses collected using a network of piezoelectric wafers was developed. A multi-class support vector machine learning algorithm was then employed to train the fused data and generate a statistical classifier which was instrumental to the classification of different damage scenarios.

Some studies considered other types of damages in pipes. For example, in [18], the empirical mode decomposition was adopted to process vibration data and to establish energy-based damage indices, which were used to identify the existence and advancement of a notch in a pipe's girth weld, backed by laboratory experiments. The numerical and experimental work in [19] utilizes acceleration estimates to quantify baseline shifts in resonant frequencies and analyses of the variance of the obtained shifts are used to construct a statistical damage detection model for identification and location of scale formation within a pipe. The study in [20] involves a laboratory experiment on a pipe with water pumped in at a controlled pressure and flow rate akin to actual operational conditions. Damage in the form of leakage was simulated by opening one of the valves installed on the pipe and the Fiber Bragg Grating sensors mounted on the pipe measured strain at varying pressures within the pipe. Support vector machine algorithms were then implemented using the collected data to predict the structural condition of the pipe under various operating conditions.

The literature review on vibration-based damage detection methods for pipes, revealed that corrosion has received less attention than other defects and none of the abovementioned methods, investigate corrosion. One reason for this disparity is that cracks are relatively easier to simulate numerically and experimentally. In some studies [9], [11] cracks have been simulated by simply reducing the material stiffness (elasticity modulus) in cracked regions (on the assumption that the damage does not alter the inertia matrix but only affects the material stiffness matrix in the eigenvalue problem); whilst, experimentally, cracks have been simulated by saw-cuts [21]. In other studies such as [22], [23] cracks are represented by massless rotational elastic springs. It may be argued that the change in mass and inertia of a structure due to the presence of a small crack is negligible, hence a mere reduction in elasticity modulus or representation by a spring is 
tolerable. However, due to the spatially complex nature of corrosion, reduction in geometric stiffness (inertia) and mass reduction (due to reduced cross-sectional area) are required for a more accurate simulation. In tubular structures, this can be achieved by reduction in wall thickness as implemented in [24] and [25].

Recently, due to advances in sensor technology and increases in cost-effective computing memory and speed, vibration-based damage identification has been on the rise [26]. These developments coupled with the fact that an increasing number of tubular structures e.g. offshore jackets and pipelines are approaching their end of life or may have encountered corrosion issues has necessitated further research in the area. Some of the recent works on the subject matter range from traditional frequency comparisons to wavelet-based methods. Frequency deviation was used in [25] to detect corrosion in pipes, and the results show that corrosion severity and frequency deviation are directly proportional, implying that frequency deviation can be used alongside other methods to quantify damage. However, the method relies on baseline features, which, in many cases, are not readily available (accessible). To overcome this setback, baseline-free methods (in this context implying without a priori knowledge of modal properties of the undamaged structure) are becoming increasingly popular. One such method [27] utilizes wavelet transformations in detecting, locating and quantifying corrosion (in the form of wallthinning) and cracks within the inner surface of a pipe. In that study, wall-thinning and cracks are modeled by smooth gradual change and abrupt change in the internal surface of the pipe, respectively. Wavelets are primarily used to detect abrupt changes (representative of cracks) and to detect the beginning and end of wall thickness changes by recovering the bending stiffness along the pipe. The study includes some numerical examples to buttress the underlying theory but lacks experimental backing. Localisation and quantification of a corrosion pit in a pipe was predicted in [28] by employing Rayleigh's law which is based on the principle of conservation of energy. In this method, damage identification is achieved from a formulation that combines the first two natural frequencies of the damaged structure only; baseline features are not required. However, the method yields two possible locations of damage on opposite sides of the pipe and the study is limited to numerical verification. Another baseline-free method presented in [21] uses the nodal displacements of a damaged structure' s modeshapes as a basis for damage detection and localisation. However, this method has not been specifically applied to pipes or corrosion damage and also gives two possible locations of damage, each on either side of the structure's longitudinal symmetrical axis. This implies that symmetry plays a significant role, especially in circular cross-sections. In [29], loss of symmetry was used to characterise corrosion in a pipe. The method involved the use of a continuous symmetry measure to quantify the amount of a particular mirror, or translational symmetry in the

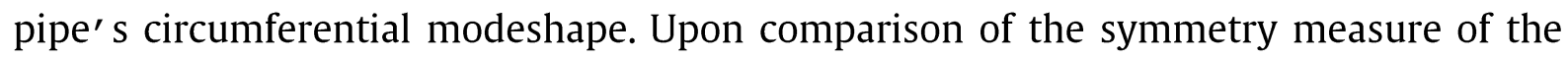
intact and damaged pipe, damage was inferred. Although, the method is backed by 
numerical and experimental work, it is limited to detection only and lacks any localisation capabilities.

This research draws on the strengths of previous methods and overcomes some of their limitations. Inspiration is taken from previous studies on the phenomenon of repeated mode pairs induced by cracks, [30] - [37], where the investigated structure is a 2dimensional ring. Here, we extend the investigation to 3-dimensional space (a pipe) and develop a method applicable for identification of various types of corrosion. The proposed method is tested on a range of pipes (corroded and uncorroded) in a series of laboratory experiments from where Local Vibration Mode Pairs, LVMPs which are characteristic of localised damage (such as corrosion pits) in axisymmetric structures are obtained and employed in the corrosion identification exercise. Also, we develop criteria which can be used to predict baseline properties of undamaged pipes to a high degree of accuracy. Hence, the proposed method has baseline-free capabilities and LVMPs can be used within existing baseline-dependent and future algorithms for damage identification in axisymmetric structures.

\section{Local Vibration Modes Pairs (LVMP)}

\subsection{Occurrence}

It is widely accepted that damage alters the natural frequency, modeshapes and damping ratios of vibrating systems. Hence, shifts in any of these modal properties are presumed to be indicative of damage. When an undamaged pipe (with free-free boundary conditions) is excited with an impact hammer, the fundamental modeshape obtainable from its response is a half-sine wave. Higher order modeshapes are composed of respective multiples of sine waves as depicted in Fig. 1.
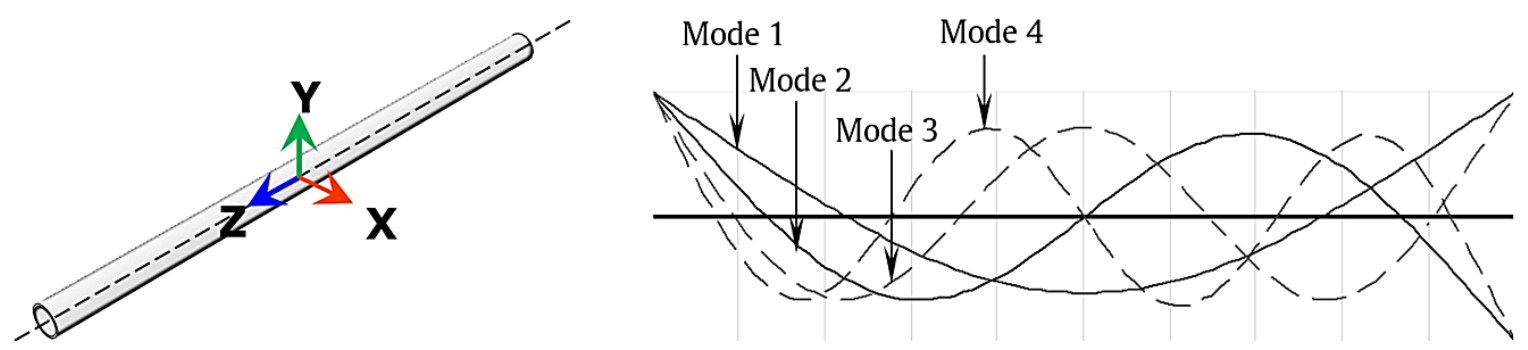

Fig. 1. Modeshapes of an Undamaged Pipe with free-free Boundary Conditions

The direction of excitation determines the orthogonal axes $\mathrm{X}$ and $\mathrm{Y}$ about which an undamaged pipe vibrates. As shown in Fig. 2 - (a), these axes are coincident with and 
orthogonal to the direction of excitation. Due to axisymmetry, in each mode, $i$, the frequency, $f$ and modeshape, $\Phi$ in the $X$ or $Y$ direction is the same, i.e. $f(X)_{i}=f(Y)_{i}$ and $\Phi(X)_{i}$ $=\Phi(Y)_{\mathrm{i}}$. However, if local damage such as a corrosion pit occurs, the pipe loses symmetry and its modal properties are altered as a consequence.

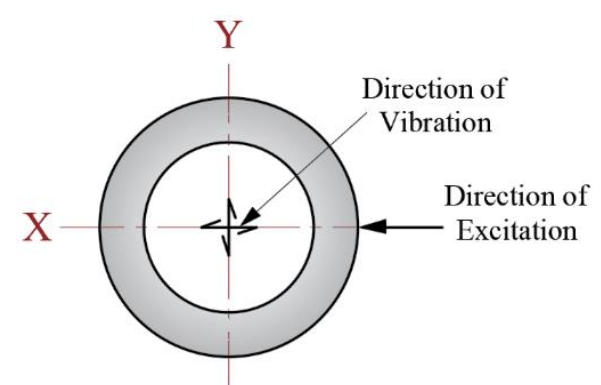

(a)

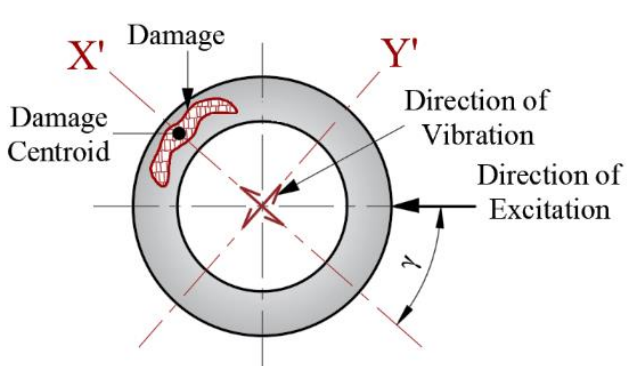

(b)

Fig. 2. Effect of Damage Orientation on the Direction of Vibration in (a) an Undamaged Pipe and (b) a Damaged Pipe

For example, in Fig. 2 - (b) it is assumed that damage is arbitrarily located within the pipe's cross-section. When the damaged pipe is excited, the axes of vibration are no longer governed by the excitation direction. Instead, the pipe vibrates along a radial axis, $\mathrm{X}^{\prime}$ through the centroid of the damage with the angle between $\mathrm{X}^{\prime}$ and the excitation direction defined as $\gamma$. The complementary vibration occurs along an axis normal to $X^{\prime}$ denoted as $Y^{\prime}$. Therefore, for a locally damaged pipe, $f\left(X^{\prime}\right)_{i} \neq f\left(Y^{\prime}\right)_{i}$ and $\Phi\left(X^{\prime}\right)_{i} \neq \Phi\left(Y^{\prime}\right)_{i}$. Each vibration mode consists of a pair of two differing frequencies and modeshapes corresponding to response in the $\mathrm{X}^{\prime}$ and $\mathrm{Y}^{\prime}$ direction. It will be shown that the vibration mode pairs are sensitive to local damage. It is important to note here that the use of the term 'local' with regard to the subjected damage relates to perturbation of circumferential (not longitudinal) symmetry. To distinguish the pairs, their components are defined as active and passive, respectively. Passive in this context, implies the vibration mode is insensitive to local damage. On the other hand, active is indicative of the vibration mode being markedly sensitive to local damage.

\subsection{Characteristics}

Fig. 3 - (a) depicts a pipe with damage in the form of a circular hole in the middle of the pipe. Due to this damage, the pipe stiffness is no longer uniform over the length, with the damaged location becoming the weakest part. When modal analysis is undertaken on this pipe, it will result in different vibration modes in the $\mathrm{X}$ and $\mathrm{Y}$ directions. Vibration in the $Y$ direction is sensitive to the presence of the local damage as shown in Fig. 3 - (b) and corresponds to a frequency less than that of the undamaged pipe, arguably due to the reduced local stiffness in the direction of vibration. On the other hand, vibration in the $\mathrm{X}$ direction is much less sensitive to the presence of local damage as shown in Fig. 3 - (c) and 
its frequency is close to that of the undamaged pipe. The 'active' and 'passive' components of this pair of modes, which occur in the damaged pipe, represent their sensitivity towards the presence of damage. In the undamaged (or axisymmetrically damaged) pipe this pair merges into a single mode (and corresponding single frequency).

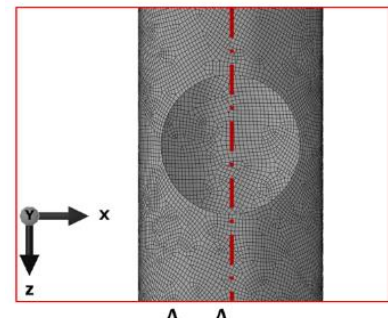

$\underline{A-A}$

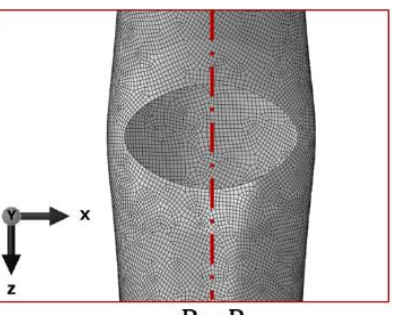

$\underline{B-B}$

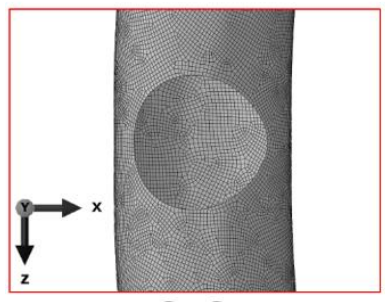

$\underline{\mathrm{C}-\mathrm{C}}$

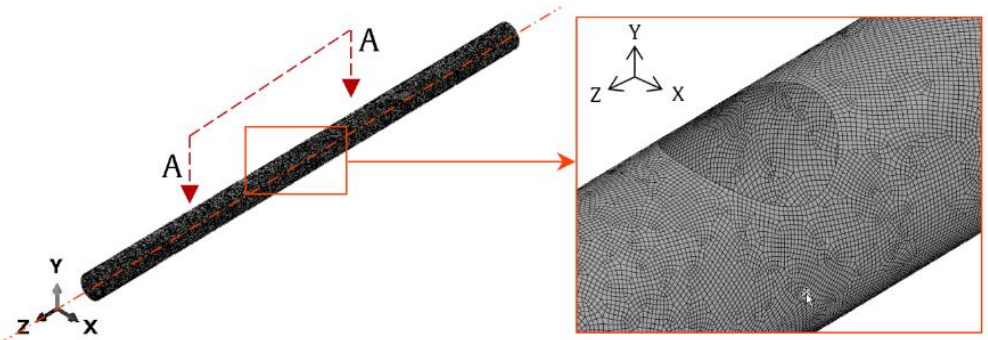

(a)

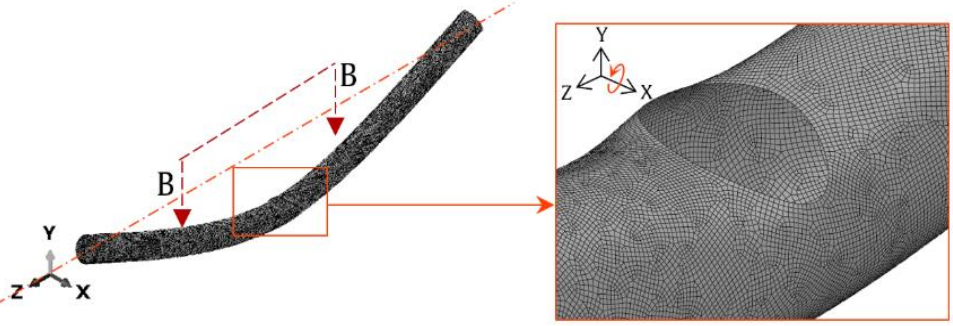

(b)

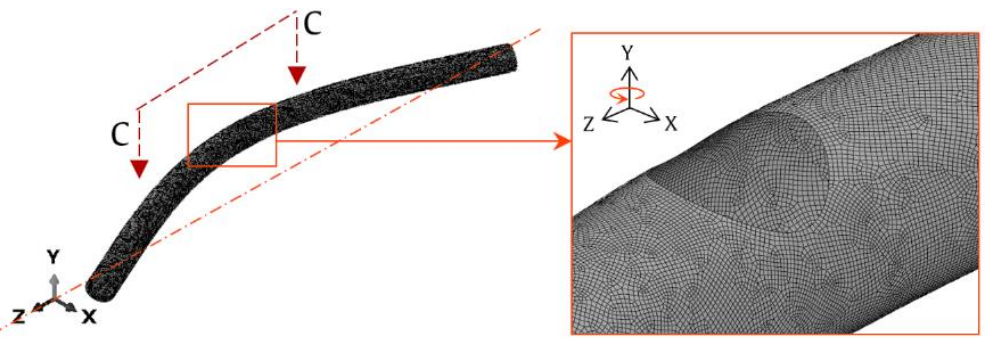

(c)

Fig. 3. Depiction of Damaged Pipe in (a) Base State (b) Active Fundamental Vibration Mode and (c) Passive Fundamental Vibration Mode

\subsection{Effect of Excitation Direction}

In an experimental setup, the pipe needs to be excited to induce vibration. In the modal tests discussed in the following sections this is done by impact hammer. Therefore, it is important to note the effect of the direction of excitation on the direction of vibration and LVMP observability. Regardless of the orientation of the damage with respect to the direction of excitation, the LVMPs obtainable through frequency response function (FRF) analysis from vibration of a damaged pipe are composed of the two components discussed above (i.e. active and passive). The axes of vibration of these modes are normal to each 
other. However, there are two exemptions to this premise. Firstly, if the pipe's damage axis happens to be perfectly normal to the direction of excitation i.e. $\gamma=90^{\circ}$ with respect to Fig. 2 -(b), only one LVMP component will be observed. The LVMP component observable depends on the profile (shape) of the damage, its longitudinal location along the pipe and the vibration mode investigated; hence it could be either active or passive. This does not imply that the unobserved LVMP component does not exist. In fact, in the second instance, where the damage axis and excitation directions happen to coincide i.e. $\gamma=0^{\circ}$, the opposite LVMP component will be observed. Summarily, if $\gamma=0$ or $90^{\circ}$, only one LVMP component per vibration mode can be observed; in all other cases, both LVMP components are observable in the corresponding FRF analysis. As such, to excite both active and passive LVMP components, the impact hammer tests need to be conducted in at least two directions with a 45-degree difference.

\subsection{Validation Criteria}

In experimental modal analysis, LVMPs are obtained via quadrature picking from FRFs. In the inevitable presence of noise, peaks corresponding to local vibration modes can be mistaken for those associated to noise. The first criterion which can be used to validate a vibration mode (including LVMPs) as adapted from [38], is embedded in Eq. (1) which represents a typical FRF, $\mathbf{h}(\mathbf{f})$ in its full complex form with real and imaginary parts.

$$
\mathbf{h}(\mathbf{f})=\frac{1-(\boldsymbol{\beta})^{2}}{\left(\mathbf{1}-(\boldsymbol{\beta})^{2}\right)^{2}+(2 \zeta(\boldsymbol{\beta}))^{2}}-\mathbf{j} \frac{2 \zeta(\boldsymbol{\beta})}{\left(1-(\boldsymbol{\beta})^{2}\right)^{2}+(2 \zeta(\boldsymbol{\beta}))^{2}}
$$

where, $\boldsymbol{\beta}$ is the ratio of the driving frequency, $\mathbf{f}$ to natural frequency, $\mathbf{f}_{\mathbf{n}}, \mathrm{j}$ is the imaginary unit and $\zeta$ is the damping ratio to critical damping. From Eq. (1) it can be seen that at resonance, (i.e. when $\boldsymbol{\beta}=1$ ), the real part of the FRF equates to zero while the imaginary part peaks. Thus, all valid vibration modes must satisfy this criterion as demonstrated in the case of an undamaged pipe in Fig. 4. 


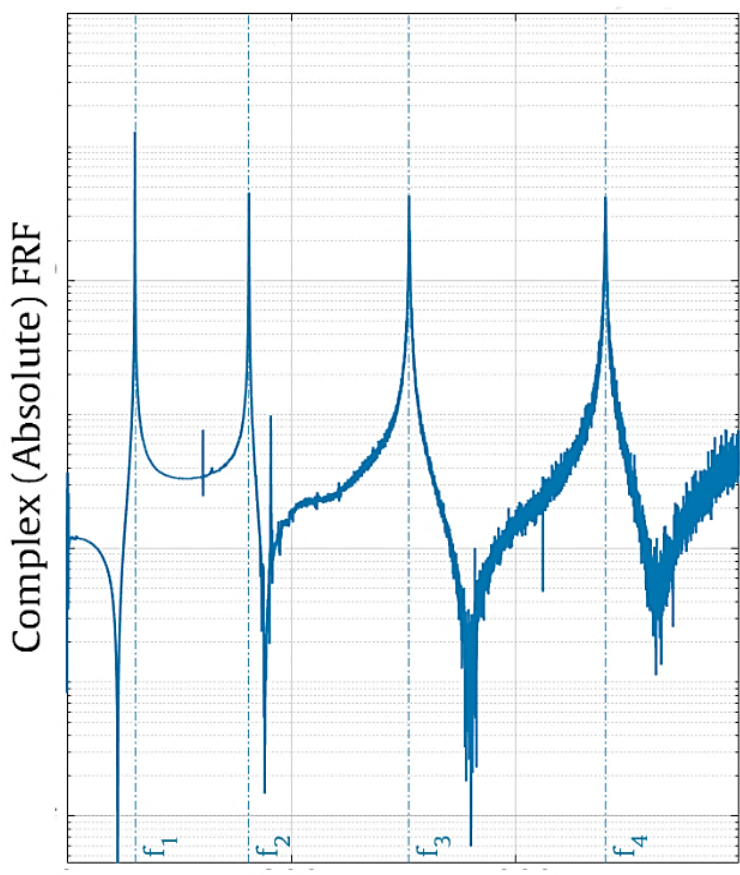

Frequency $(\mathrm{Hz})$

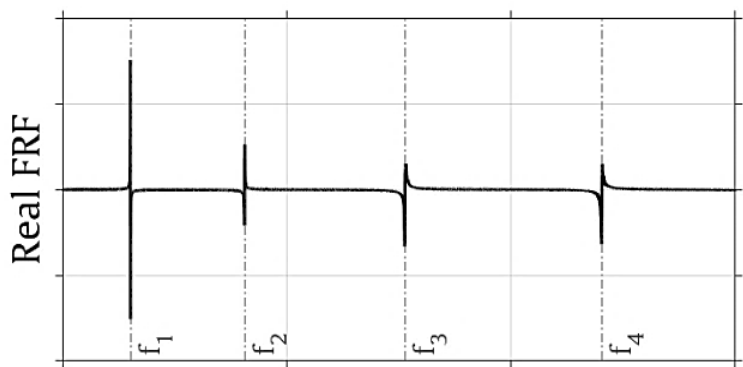

Frequency $(\mathrm{Hz})$

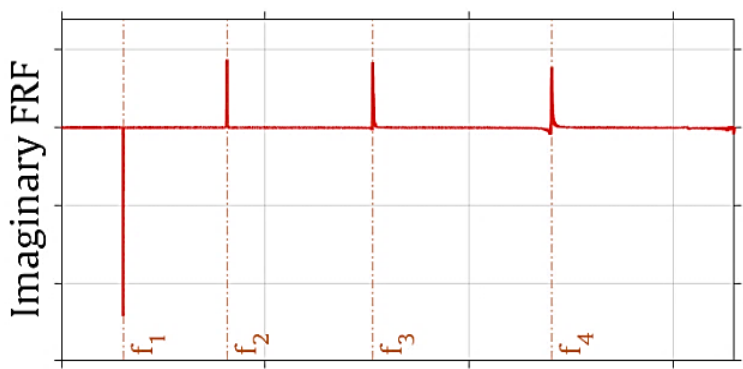

Frequency $(\mathrm{Hz})$

Fig. 4. An Example of undamaged pipe FRFs showing first four vibration modes

In addition to the above, other empirical criteria pertinent to LVMPs in axisymmetric structures are listed below. These criteria were deduced from an investigation of various damage scenarios in pipes which will be presented and discussed in detail in section 3 .

i) LVMPs consist of a pair, one representing an active mode and the other a passive mode.

ii) The difference between active and passive modes is typically around $10 \%$ or less (based on the findings of this research).

iii) The modeshapes of both active and passive local modes are similar and are composed of the same number of half-sine waves.

To illustrate the above criteria, Fig. 5 presents FRF plots of the same pipe (whose FRF in an undamaged state is shown in Fig. 4) but with local damage introduced in the form of a hole through the pipe. In this figure, the LVMPs (with subscripts ' $A$ ' and ' $P$ ' for active and passive components respectively) are observable in all four investigated modes. 

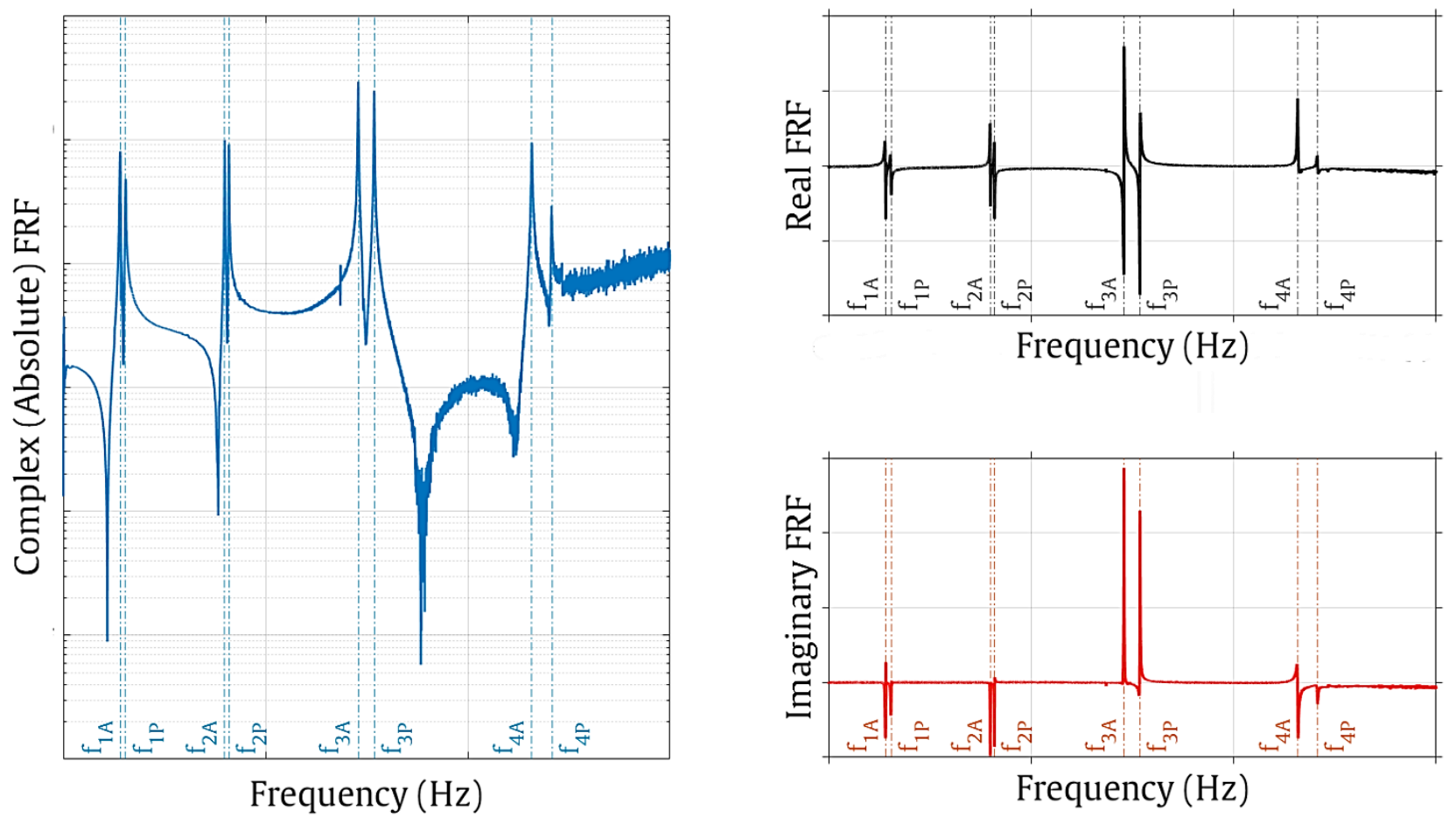

Fig. 5. An Example of locally damaged pipe FRFs showing first four LVMPs

\section{Modal Test and Analysis}

\subsection{Test Specimens}

The test specimens comprised of 4-inch aluminium pipes (grade AL 6082) with experimentally validated material and geometric properties given in Table 2.

Table 2 Properties of Test Specimen

\begin{tabular}{cccccccc}
\hline $\begin{array}{c}\text { Material } \\
\text { Designation }\end{array}$ & $\begin{array}{c}\text { Elasticity } \\
\text { Modulus } \\
\mathrm{MPa}\end{array}$ & Density & $\begin{array}{c}\text { Poisson' } \mathrm{s} \\
\text { Ratio } \\
\mathrm{kg} \mathrm{m}^{-3}\end{array}$ & $\begin{array}{c}\text { Length } \\
\left(\mathrm{L}_{\text {pipe }}\right) \\
\mathrm{mm}\end{array}$ & $\begin{array}{c}\text { Outside } \\
\text { Diameter } \\
\mathrm{mm}\end{array}$ & $\begin{array}{c}\text { Wall } \\
\text { Thickness } \\
\mathrm{mm}\end{array}$ & $\begin{array}{c}\text { Unit } \\
\text { Mass } \\
\mathrm{kg} \mathrm{m}^{-1}\end{array}$ \\
\hline AL 6082 T6 & 69,858 & 2,691 & 0.33 & 2000 & 101.64 & 6.37 & 5.13 \\
\hline
\end{tabular}

A total of 8 pipes were tested; 1 undamaged pipe (baseline) and 7 damaged pipes with various artificially inflicted damage patterns ranging from a thickness-recessed longitudinal strip to localised rings and through-thickness holes to represent possible corrosion scenarios as shown in Fig. 6 and schematically in Fig. 7. 


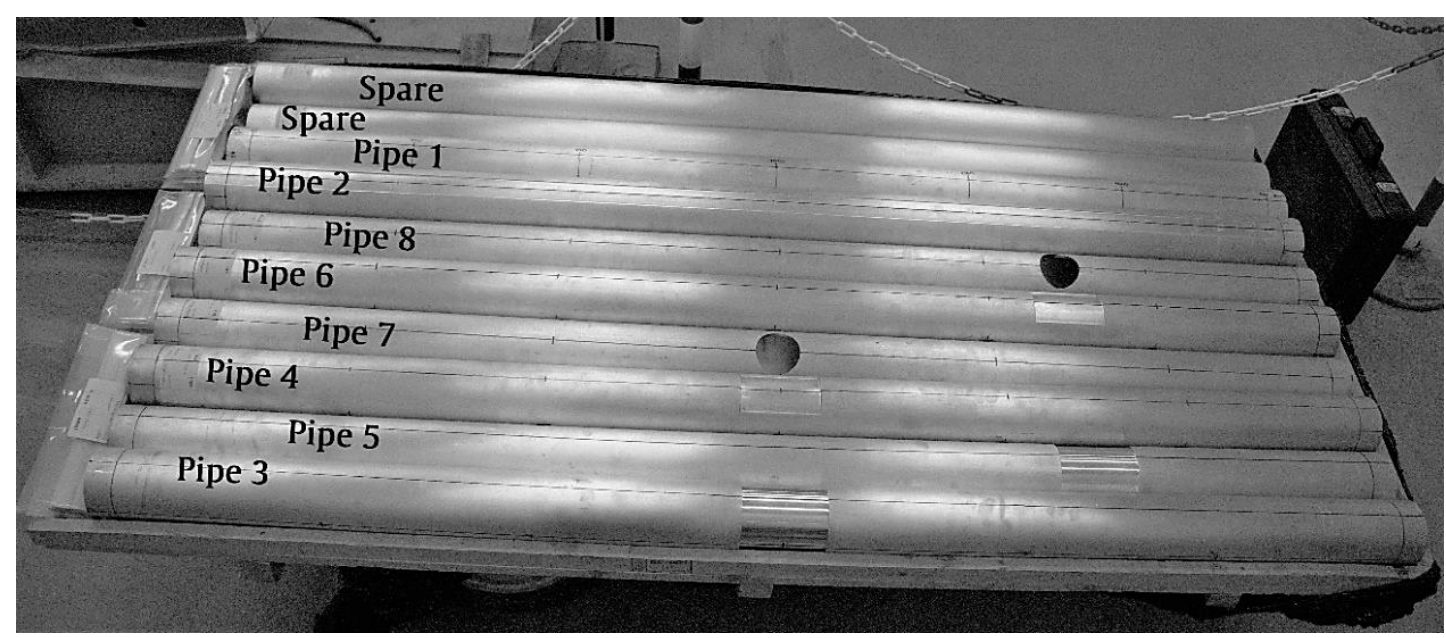

Fig. 6. A Photograph of the Investigated Pipe Specimens

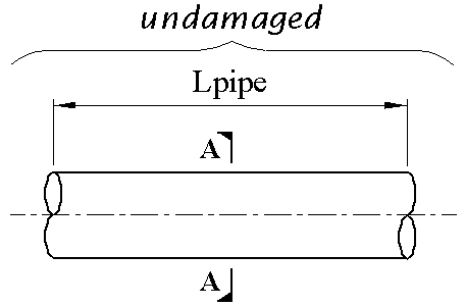

Pipe 1

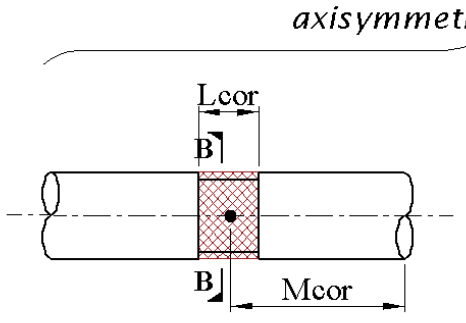

Pipe 3

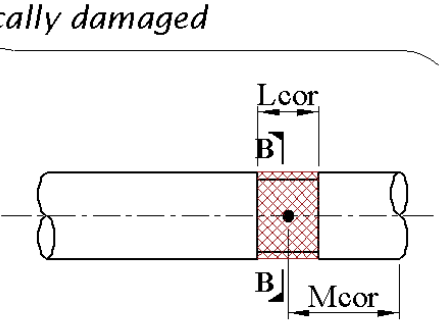

Pipe 5

non-axisymmetrically damaged

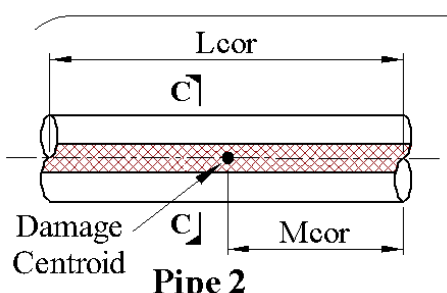

Pipe 2

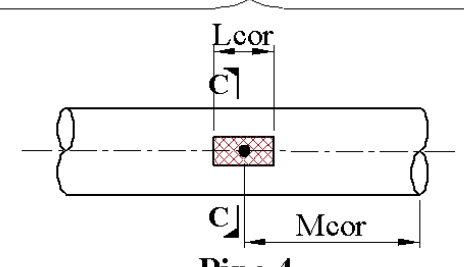

Pipe 4

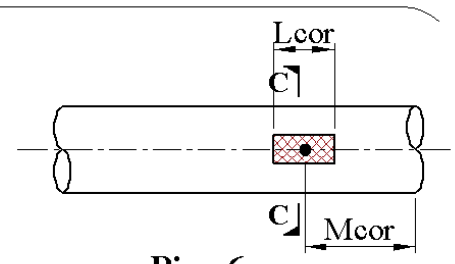

Pipe 6

Test Case Cross-Sections

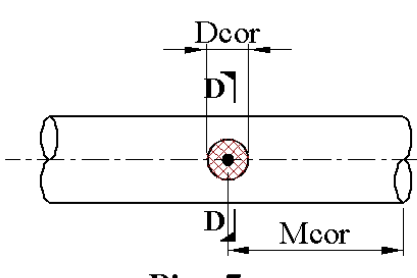

Pipe 7

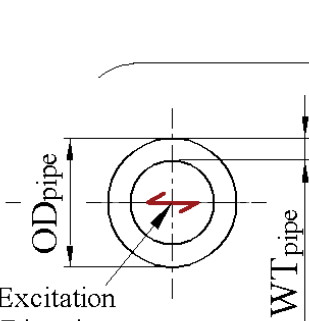

Direction A-A
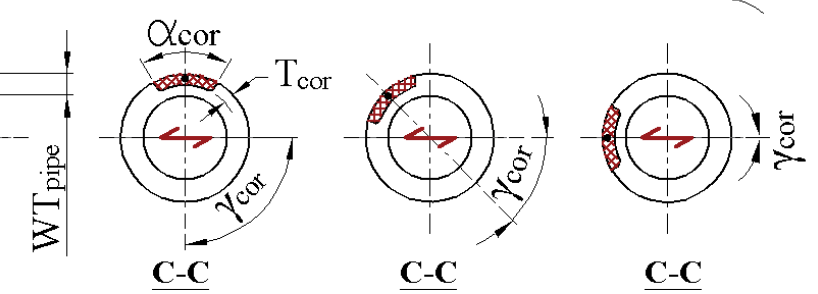

C-C (Case 1) (Case $2 \mathrm{a}, 4 \mathrm{a}, 6 \mathrm{a}) \quad$ (Case $2 \mathrm{~b}, 4 \mathrm{~b}, 6 \mathrm{~b})$ (Case $2 \mathrm{c}, 4 \mathrm{c}, 6 \mathrm{c})$

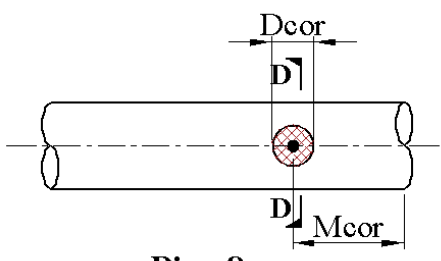

Pipe 8

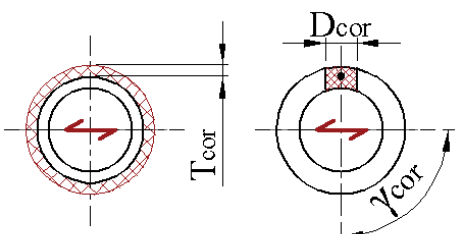

B-B

(Case $3 \& 5$ )

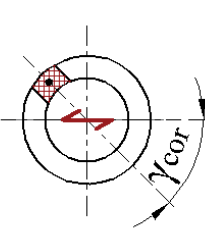

D-D

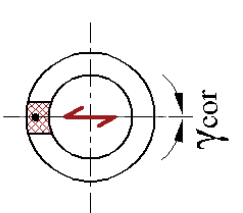

D-D
D-D

(Case 7a \& 8a)

(Case $7 \mathrm{~b} \& 8 \mathrm{~b}$ ) (Case $7 \mathrm{c} \& 8 \mathrm{c}$ )

Fig. 7. Schematics of the Pipe Specimens and Test Case Cross-Sections 
The dimensions of the damage parameters defined in Fig. 7 are given in Table 3. Each pipe corresponds to a test case; however, for the non-axisymmetrically damaged Pipes (2, 4, 6, 7 and 8), three sub-case suffixes ' $a{ }^{\prime},{ }^{\prime} b^{\prime}$ and ' $c$ ' are developed by rotating the relative angle, $\gamma_{c o r}$ between the local damage centroid and the excitation (horizontal) axis by 90,45 and 0 deg respectively. The main purpose of this rotation is to maximise the possibility of capturing LVMPs during the test as explained in Section 2.3. In addition, the percentage of corrosion per cross-sectional area, $C S A_{c o r}$ and entire pipe volume, $V O L_{c o r}$ for each test case are enlisted in Table 3.

Table 3 Pipe Specimens,Test Cases and their Respective Damage Properties

\begin{tabular}{|c|c|c|c|c|c|c|c|c|c|c|c|}
\hline $\begin{array}{l}\text { Pipe } \\
\text { Label }\end{array}$ & $\begin{array}{l}\text { Test } \\
\text { Case }\end{array}$ & $\begin{array}{c}\text { Corrosion } \\
\text { type }\end{array}$ & $\begin{array}{c}\text { Damage } \\
\text { symmetry }\end{array}$ & $\begin{array}{l}\mathrm{T}_{\text {cor }} \\
\mathrm{mm}\end{array}$ & $\begin{array}{l}\mathrm{L}_{\mathrm{cor}} \\
\mathrm{mm}\end{array}$ & $\begin{array}{l}\mathrm{D}_{\text {cor }} \\
\mathrm{mm}\end{array}$ & $\begin{array}{l}\mathrm{M}_{\mathrm{cor}} \\
\mathrm{mm}\end{array}$ & $\begin{array}{l}\alpha_{\text {cor }} \\
\text { deg. }\end{array}$ & $\begin{array}{l}\gamma_{\text {cor }} \\
\text { deg. }\end{array}$ & $\begin{array}{c}\mathrm{CSA}_{\text {cor }} \\
\%\end{array}$ & $\begin{array}{c}\mathrm{VOL}_{\mathrm{cor}} \\
\%\end{array}$ \\
\hline 1 & 1 & none & - & - & - & - & - & - & - & - & - \\
\hline 2 & $2 a$ & long. strip & $\begin{array}{c}\text { non- } \\
\text { axisymmetric }\end{array}$ & 2 & 2000 & - & 1000 & 45 & 90 & 4.1 & 4.1 \\
\hline$"$ & $2 b$ & $"$ & " & $"$ & $"$ & - & $"$ & $"$ & 45 & $"$ & $"$ \\
\hline$"$ & $2 c$ & $"$ & " & $"$ & $"$ & - & $"$ & " & 0 & $"$ & $"$ \\
\hline 3 & 3 & local ring & axisymmetric & 3 & 125 & - & 1000 & 360 & - & 48.9 & 3.1 \\
\hline 4 & $4 a$ & local pit & $\begin{array}{c}\text { non- } \\
\text { axisymmetric }\end{array}$ & 4 & 125 & - & 1000 & 90 & 90 & 16.1 & 1.0 \\
\hline$"$ & $4 \mathrm{~b}$ & $"$ & 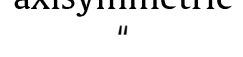 & $"$ & $"$ & - & $"$ & $"$ & 45 & $"$ & $"$ \\
\hline$"$ & $4 c$ & " & $"$ & $"$ & $"$ & - & $"$ & $"$ & 0 & $"$ & $"$ \\
\hline 5 & 5 & local ring & axisymmetric & 3 & 125 & - & 500 & 360 & - & 48.9 & 3.1 \\
\hline 6 & $6 a$ & local pit & $\begin{array}{c}\text { non- } \\
\text { axisymmetric }\end{array}$ & 4 & 125 & - & 500 & 90 & 90 & 16.1 & 1.0 \\
\hline$"$ & $6 b$ & $"$ & " & $"$ & $"$ & - & $"$ & $"$ & 45 & $"$ & $"$ \\
\hline$"$ & $6 c$ & $"$ & $"$ & $"$ & $"$ & - & $"$ & $"$ & 0 & $"$ & $"$ \\
\hline 7 & $7 a$ & local pit & $\begin{array}{c}\text { non- } \\
\text { axisymmetric }\end{array}$ & hole & - & 72 & 1000 & - & 90 & 25.1 & 0.8 \\
\hline$"$ & $7 b$ & $"$ & (1) & $"$ & - & $"$ & $"$ & - & 45 & $"$ & $"$ \\
\hline$"$ & $7 c$ & $"$ & $"$ & $"$ & - & $"$ & $"$ & - & 0 & $"$ & " \\
\hline 8 & $8 a$ & local pit & $\begin{array}{c}\text { non- } \\
\text { axisymmetric }\end{array}$ & hole & - & 72 & 500 & - & 90 & $"$ & $"$ \\
\hline$"$ & $8 b$ & $"$ & 4 & $"$ & - & $"$ & $"$ & - & 45 & $"$ & $"$ \\
\hline$"$ & $8 c$ & " & $"$ & " & - & $"$ & " & - & 0 & $"$ & $"$ \\
\hline
\end{tabular}

\subsection{Test Setup}

The test was setup and performed in the Structural Engineering Laboratory of the University of Surrey, Guildford, UK. The test space was free from external vibrations with surrounding temperatures averaging 26 degrees Celsius for the test duration. A photograph and schematic of the test setup are presented in Fig. 8 and Fig. 9 respectively.

In each test case, the specimen was suspended from inextensible cables, hung from standard trestles at $40 \mathrm{~mm}$ from either end. Within each cable, tension springs, (LE 075E 04 S) supplied by Lee Spring, UK and digital Mass Scales were attached. The springs allowed the introduction of free-free boundary conditions in all degrees of freedom of the 
pipe while the mass scales enabled measurement of the specimen's mass. Seven uniaxial Isotron accelerometers (mass $3.5 \mathrm{~g}$ each), model: $256-100$ by Endevco, USA were attached along a horizontal axis as shown in Fig. 11 (i.e. at 270 degrees circumferentially and at seven longitudinal positions: i.e. at 5, 340, 640, 1000, 1360, 1660 and 1995mm from the left end) to record response signals. Notably, the ratio of the weight of each accelerometer to specimen weight is less than $0.04 \%$ and thus does not have a significant effect on the recorded signals. Two 4-channel Input Modules connected to Data Acquisition (DAQ), Chassis cDAQ-9178 by National Instruments, USA were employed for data acquisition. Each accelerometer was connected to a channel on the DAQ module while the remaining channel was reserved for the excitation source (Modal Hammer, No. 2304 by Endevco). The frequency limit of the accelerometers ranged from 2,500 to $10,000 \mathrm{~Hz}$ (with at least $97 \%$ accuracy). Hence, a sampling frequency, $\mathrm{f}_{\mathrm{s}}$ circa $3600 \mathrm{~Hz}$ was adopted for the experiments as the maximum expected theoretical frequency, $\mathrm{f}_{\max }$ of the highest investigated mode (i.e. vibration mode 4 ) was less than $1800 \mathrm{~Hz}$. The chosen sampling frequency is based on Shannon's sampling theorem which states that $f_{s}>2 f_{\max }$ as described in [38]. The acquired data was visualised, processed and stored on a Dell Precision 5520, Laptop Computer via National Instruments' , LabView, Version 18.0.1f.

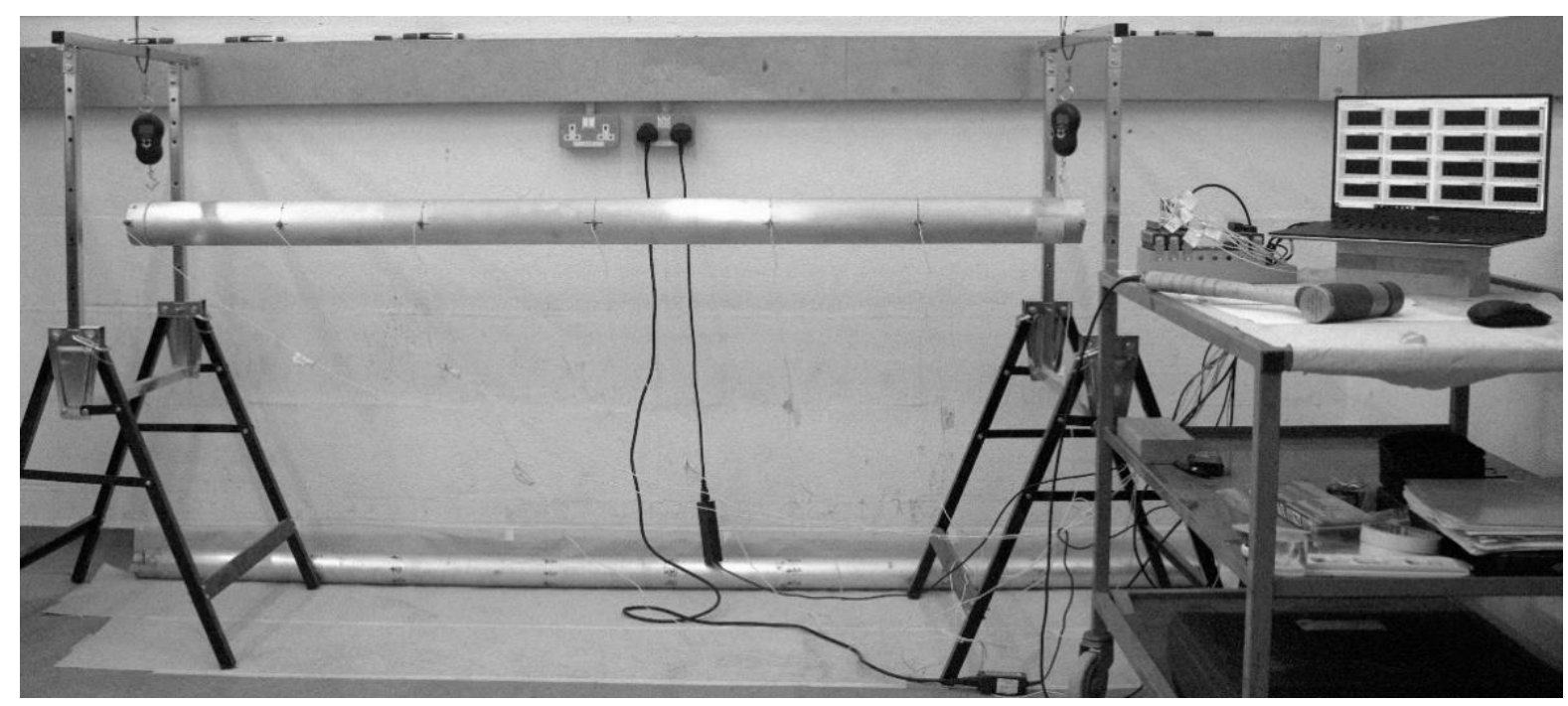

Fig. 8. A Photograph of the Laboratory Test Setup showing Pipe 1 suspended in free-free boundary condition 


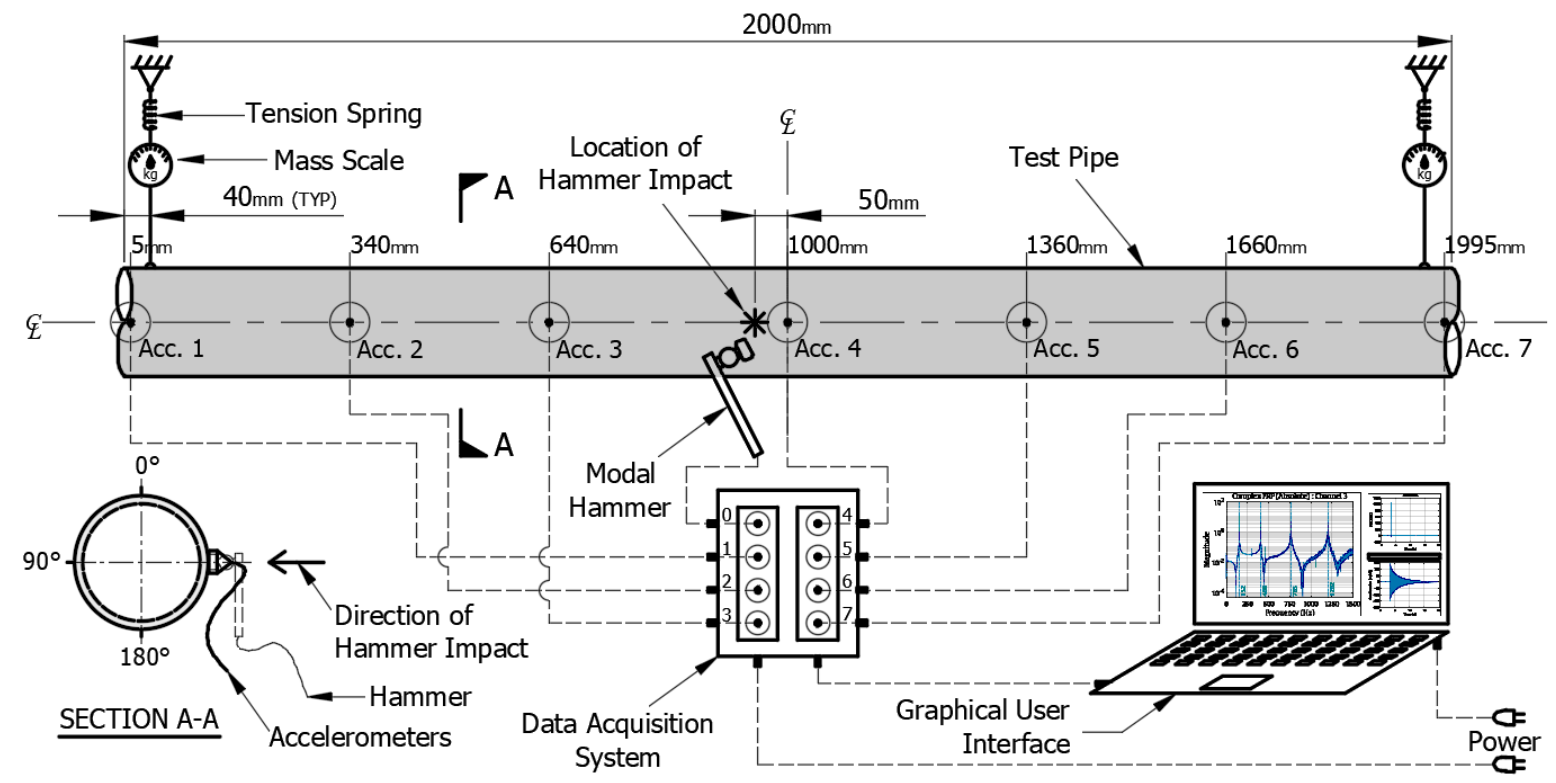

Fig. 9. A Schematic Representation of the Laboratory Test Setup

\subsection{Test Procedure}

The test procedure adopted in this research was achieved from a wider study in [40] which included tests for benchmarking and repeatability of derived modal properties. The study also checked the sensitivity of modal properties to different hammer impact and sensor locations. Consequently, it was found that the test procedure described below is capable of producing repeatable results and the obtained results were consistent with those derived from finite element models e.g. frequency deviation was less than $1 \%$ up to the fourth vibration mode. Also, it was found that the location of hammer impact or sensor positioning did not have any significant effect on the obtained results.

In the adopted procedure, the specimen for each test case was excited by impact from the modal hammer at approximately $50 \mathrm{~mm}$ from the centre of the pipe in the $90-270 \mathrm{deg}$ (horizontal) direction as shown in Fig. 9. Seven hammer hits were recorded for each case in Table 3 resulting in a total of 126 signals (i.e. 18 test cases $x 7$ hammer hits) being analysed. Noisy signals were minimised following guidance from [38]. This involved a series of trial impacts to determine the hit method, intensity and impact hammer tip capable of adequately exciting the structure with single time-domain peaks (free from double-hits). Consequently, force impulses of between 0.8 to $1.0 \mathrm{kN}$ were adopted as shown typically for the excitation signal plot for Case 1 in Fig. 10 - (a). Based on Fig. 10 (b), the broadband frequency range of the impact hammer used is between 0 to $\sim 1800 \mathrm{~Hz}$ (i.e. half of the sampling rate) with similar hammer frequency ranges recorded in all other test cases, which is aligned with Shannon's stheorem. It is also obvious that below $1200 \mathrm{~Hz}$, the noise level is low. Noise due to aliasing was minimised by utilisation of a low-pass 
filter during signalling while an exponential window was used to subdue noise due to leakage.

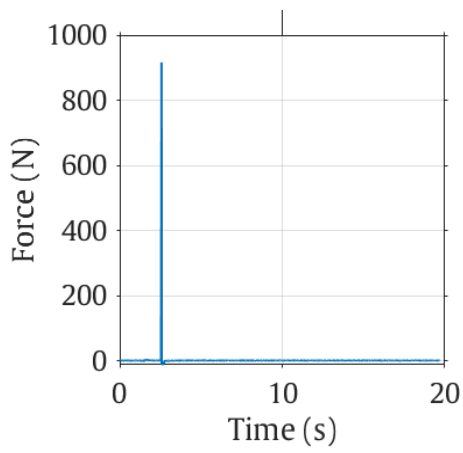

(a)

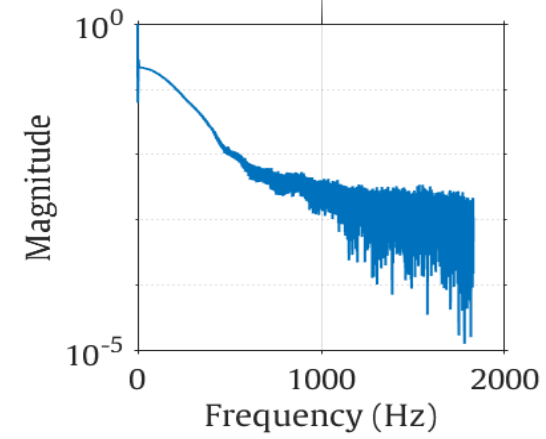

(b)

Fig. 10. Typical Impact Hammer Signal for Test Case 1 in (a) Time-domain and (b) Frequency-domain

\subsection{Modal Analysis}

To analyse the recorded vibration data, a dedicated MATLAB script was developed inhouse based on modal analysis [38]. The script can perform fast-Fourier Transform (FFT) on the acquired data and deliver the identified modal parameters, including natural frequencies and mode shapes. Also, the script is capable of deriving classical indicators such modal assurance criteria (MAC), modeshape curvature, modal strain energy etc.

Each test case comprised of 7 excitation and 49 (i.e. 7 excitations $x 7$ sensors) response signals. Therefore, for each hammer hit, i, 7 FRFs corresponding to each of the sensor locations, $\mathbf{j}$, were obtained. The obtained FRFs were then averaged at each sensor location to arrive at 7 aggregated FRFs for each test case according to Eq. (2).

$$
\mathbf{h}(\mathbf{f})_{\mathbf{j}}=\left(\frac{\sum_{\mathbf{i}=\mathbf{1}}^{\mathrm{I}} \mathbf{h}(\mathbf{f})_{\mathbf{i}}}{\mathbf{I}}\right)_{\mathbf{j}}
$$

where, $\mathbf{h}(\mathbf{f})_{\mathbf{j}}$ is the aggregated FRF from a total number of I hits, at the $\mathrm{j}$-th sensor position. Since the aggregated FRFs for each case were in their complex form; they were further decomposed into their real and imaginary parts to enable verification of valid vibration modes according to the process described in Section 2.4. Following validation, frequencies of valid modes were determined by quadrature picking of the peaks in the aggregated FRFs with frequencies from all sensors identical to one decimal point. Modeshapes were derived from the peaks of respective vibration modes of the aggregated imaginary FRFs in accordance with the methods described in [38]. 


\section{Results}

\subsection{Modal Properties}

\subsubsection{Frequencies}

It was observed that the aggregated FRFs and corresponding frequencies from each sensor were identical for any given test case; hence the FRF from only one sensor location is presented for each test case. Sensor position 3 at $640 \mathrm{~mm}$ from the left end of the pipe is randomly selected for this purpose. Adoption of data from any other sensor position will yield identical results, as can be verified from the test data in [39].

Fig. 11 presents plots of the representative FRFs for the investigated cases highlighting the frequencies, corresponding to each valid vibration mode, $i$ with subscript ' $A$ ' and ' $P$ ' for active and passive modes respectively. Notably, for the non-axisymmetrically damaged cases, FRFs for sub-case ' $b$ ' only are presented. This is because, in sub-cases ' $a$ ' and ' $c$ ', the vibration and excitation directions are normal and coincident respectively. Therefore, only one LVMP component is obtainable from these sub-cases; whereas in the ${ }^{\prime} b$ ' sub-cases, both LVMP components are observable as explained in Section 2.3. 


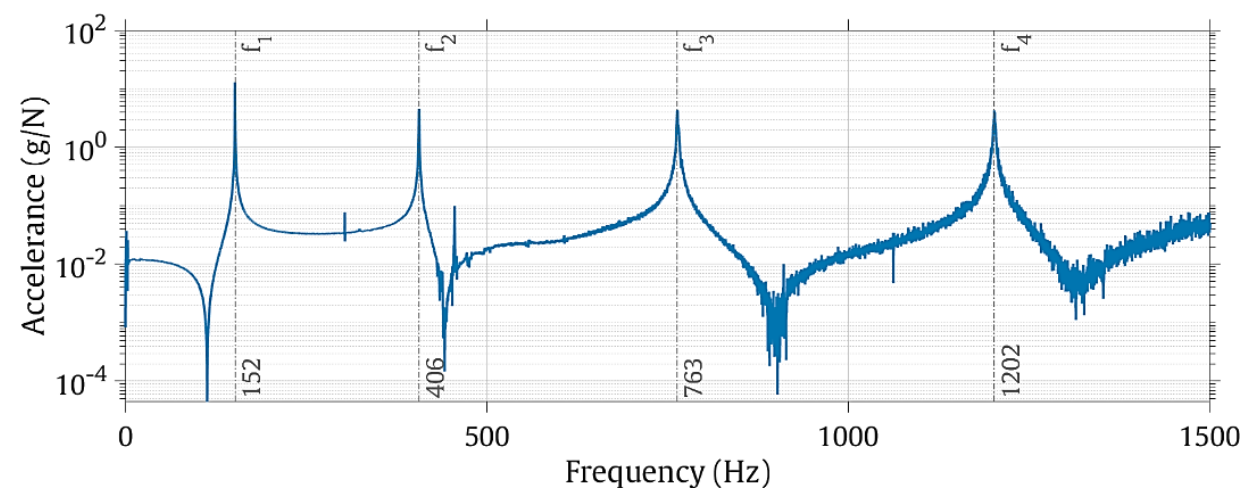

(a) Case 1 - Baseline

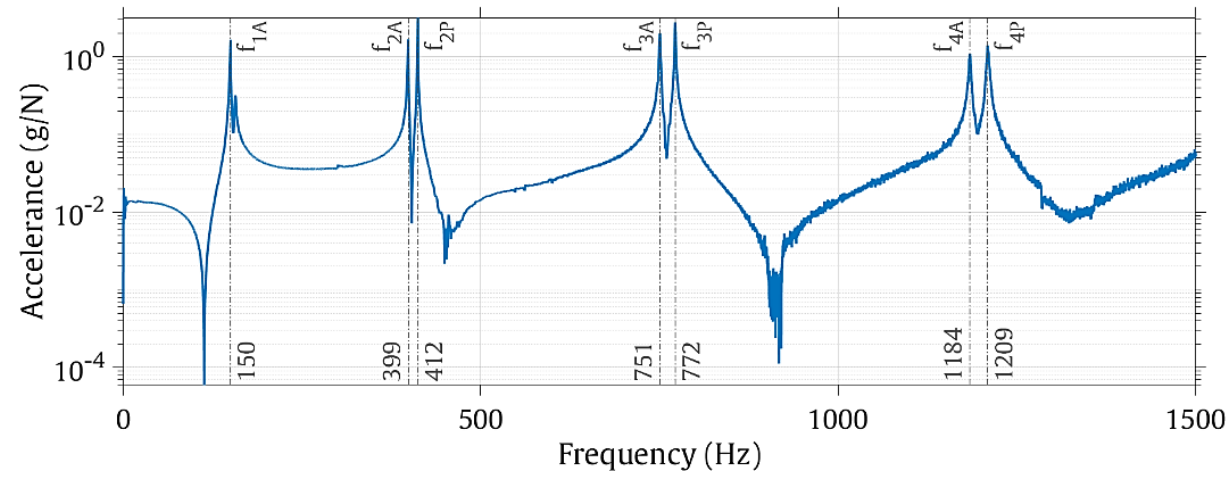

(b) Case 2b

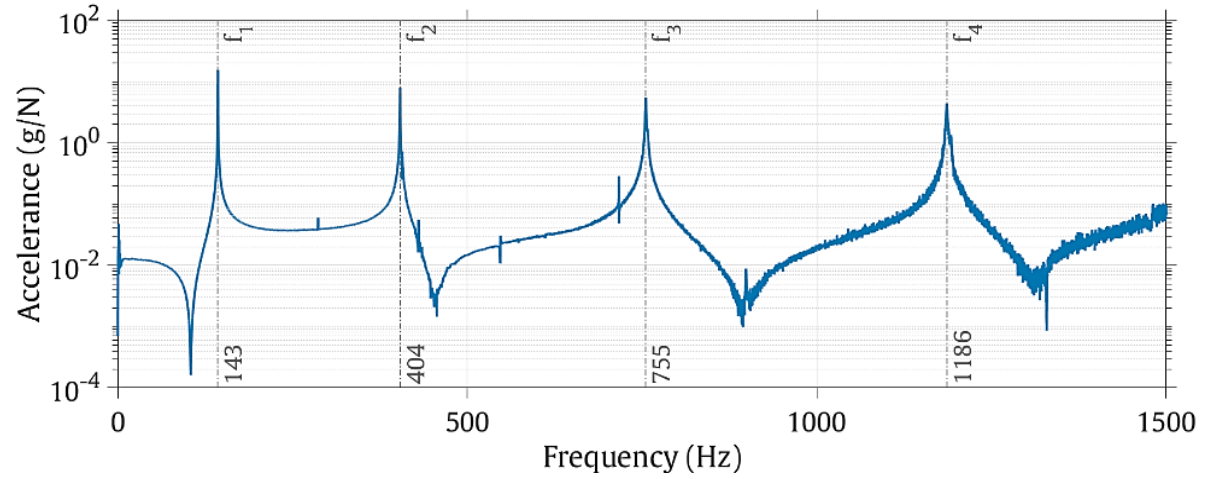

(c) Case 3

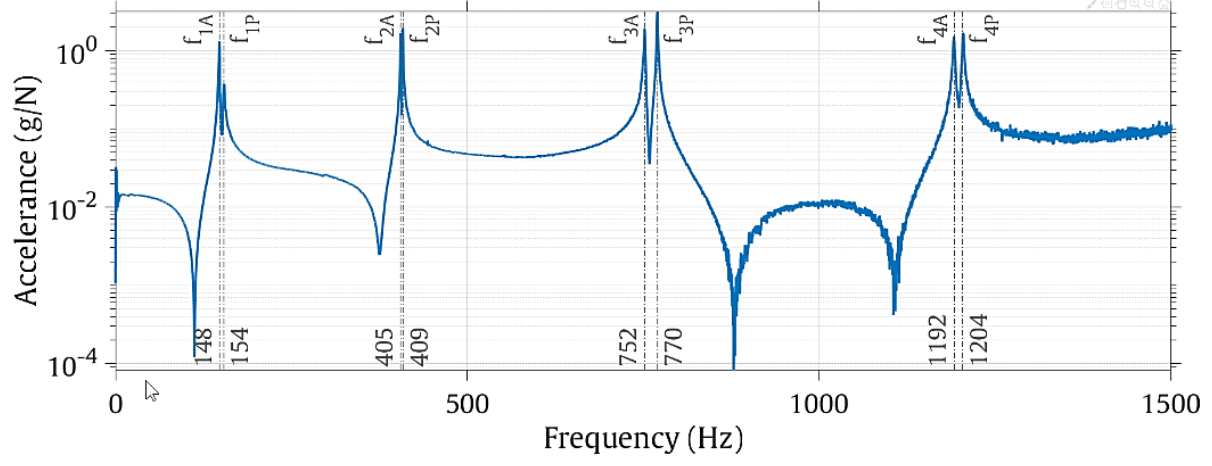

(d) Case 4b

Fig. 11. FRF Plots of Selected Test Cases

(a) Case 1 - Baseline, (b) Case 2b, (c) Case 3, (d) Case 4b,

(e) Case 5, (f) Case 6b, (g) Case 7b and (h) Case 8b 


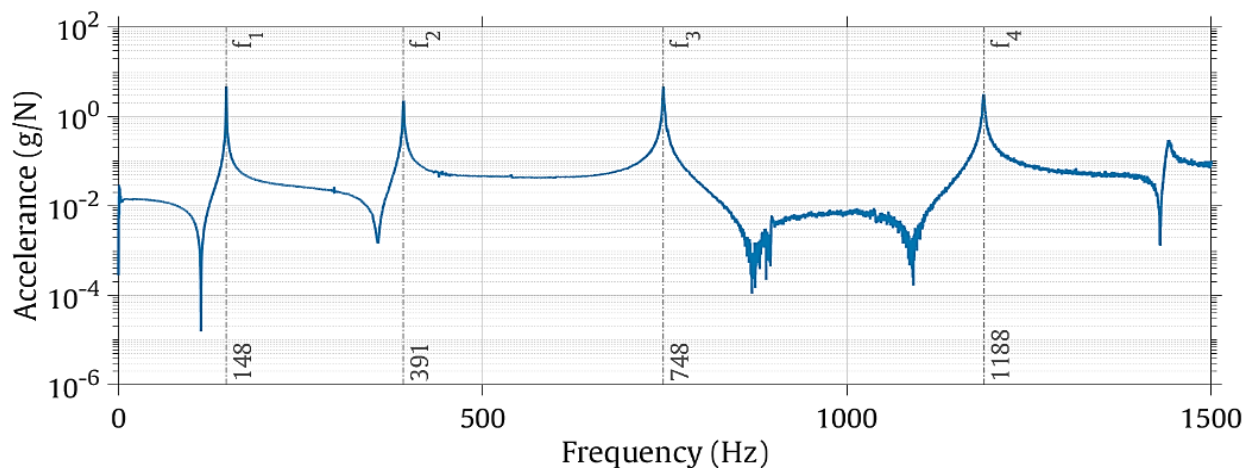

(e) Case 5

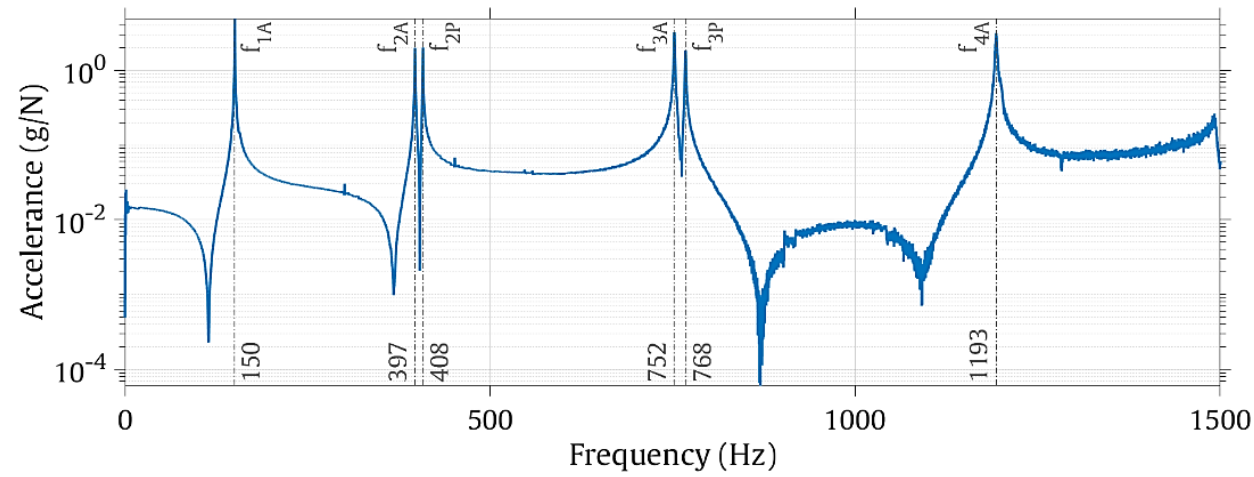

(f) Case 6b

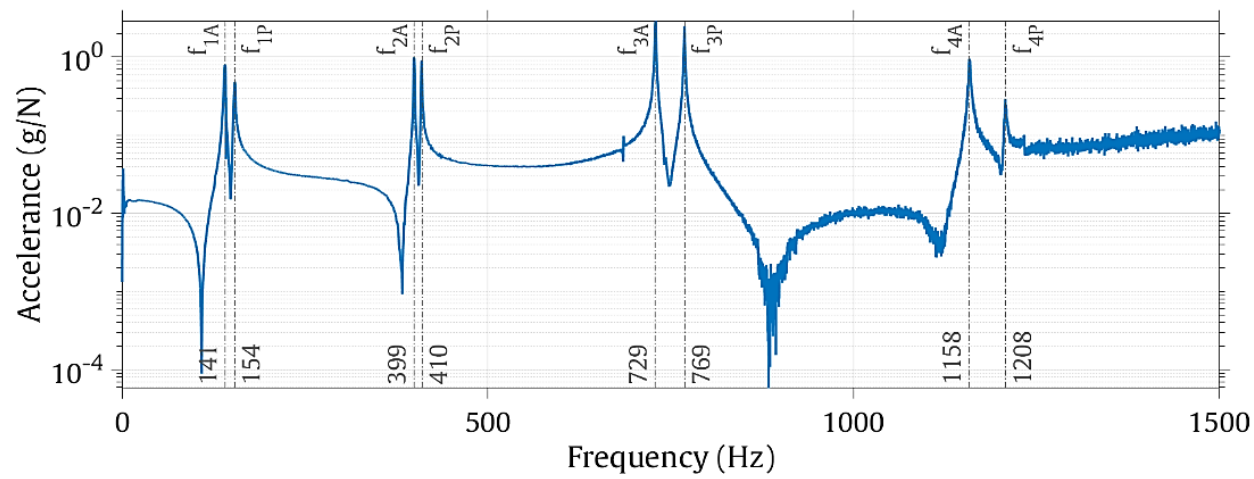

(g) Case 7b

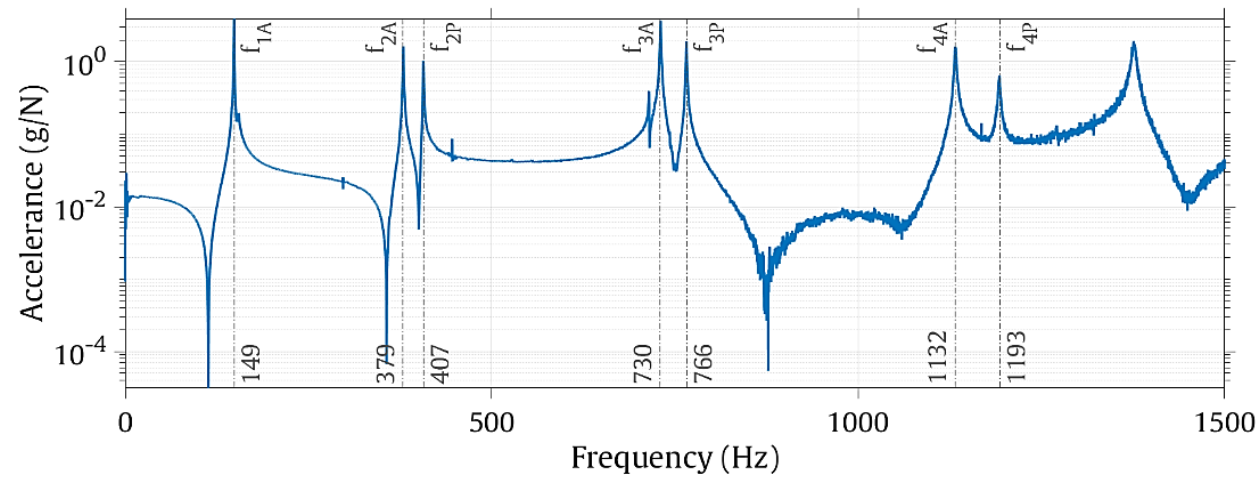

(h) Case 8b

Fig. 11 Cont $^{\prime} \mathrm{d}$

Page | 18 


\subsubsection{Modeshapes}

Seven eigenvector co-ordinates corresponding to each of the sensors were obtained for the first four valid modes in each case; these co-ordinates were normalised and are listed in the Appendix. Next, a cubic spline was fitted to raw co-ordinates to obtain the curved modeshapes for the vibration modes in each case as shown in Fig. 12. The modeshapes for the axisymmetric cases and sub-cases ' $a$ ' and ' $c$ ' of the non-axisymmetric cases are presented. Included in these plots are Nodal Points, $\mathbf{N P}_{\mathbf{i j}}$, where, $\mathbf{i}$ denotes the vibration mode number and $\mathbf{j}$ is the serial number of the nodal point per mode.

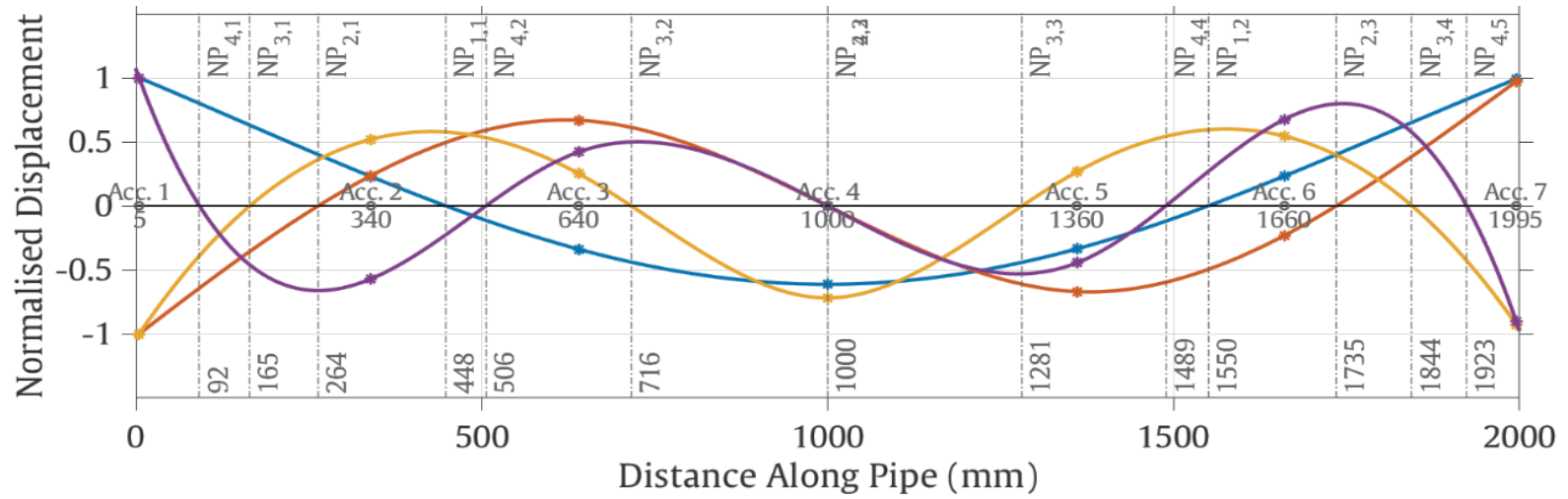

(a) Case 1 - Baseline

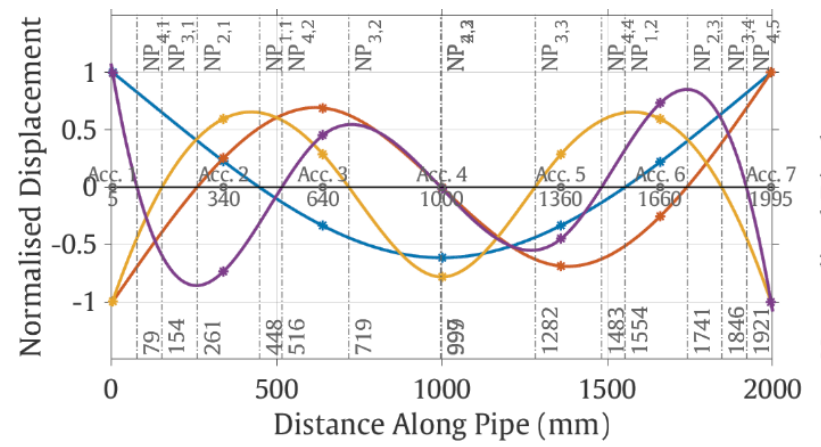

(b) Case 2a

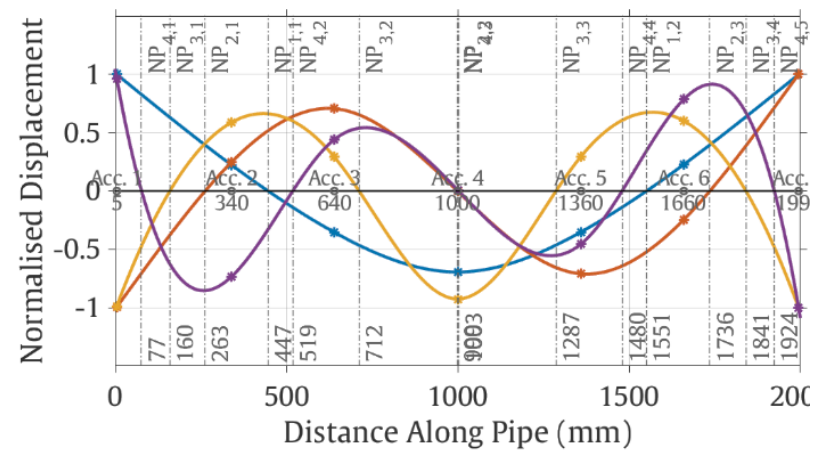

(d) Case 3

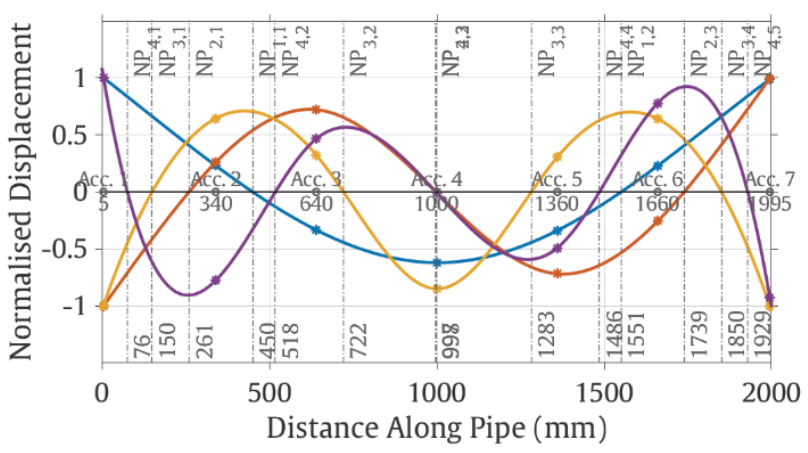

(c) Case 2c

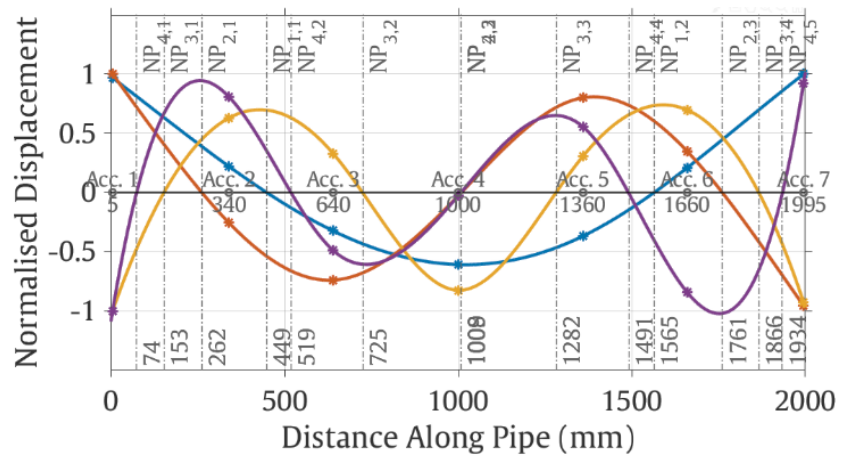

(e) Case 5

Fig. 12. Modeshapes and Nodal Points of the Selected Test Cases

(a) Case 1 - Baseline, (b) Case 2a, (c) Case 2c, (d) Case 3, (e) Case 5, (f) Case 4a, (g) Case 4c,

(h) Case 6a, (i) Case 6c, (j) Case 7a, (k) Case 7c, (l) Case 8a, and (m) Case 8c 


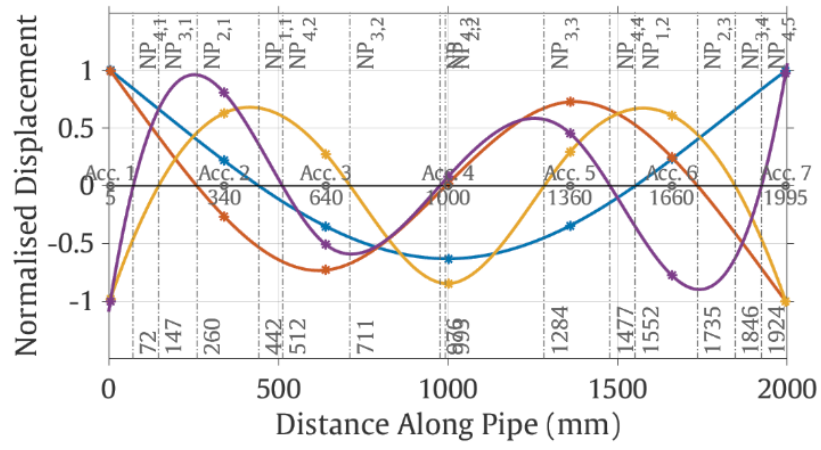

(f) Case 4a

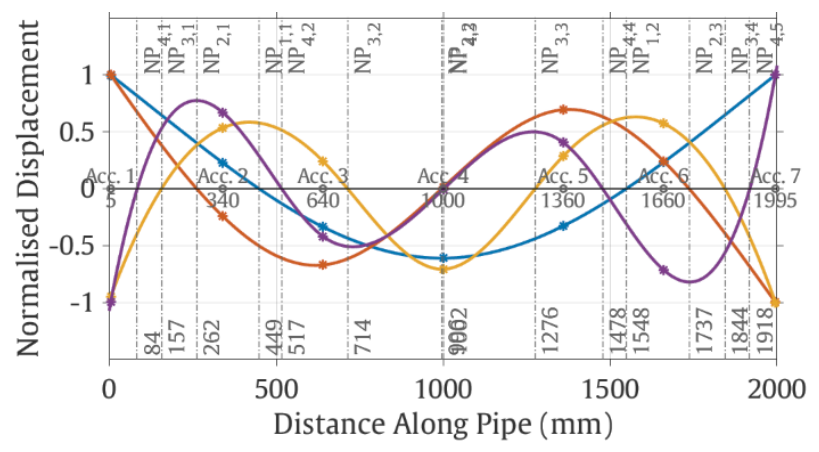

(h) Case 6a

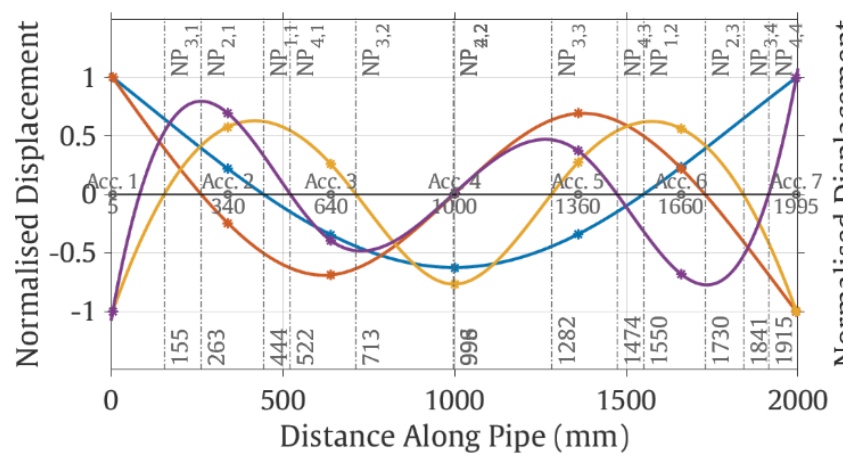

(j) Case 7a

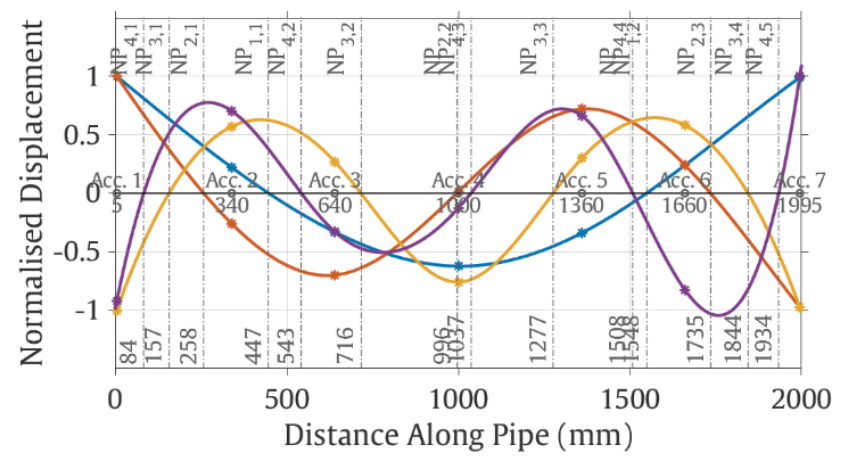

(l) Case 8a

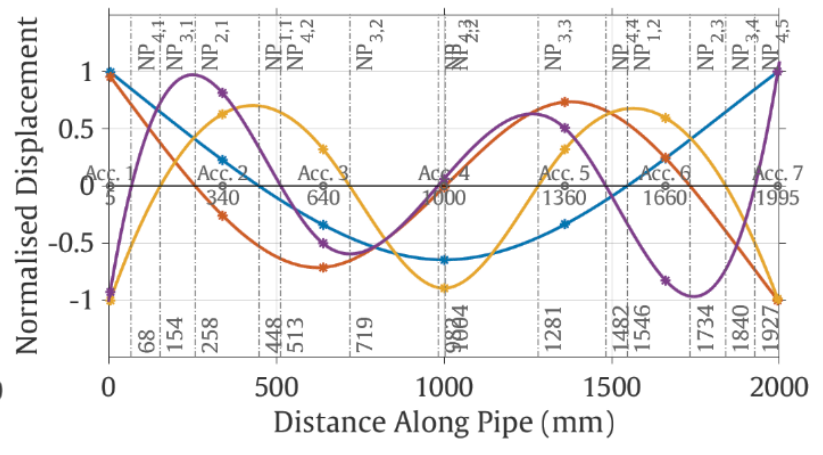

(g) Case 4c

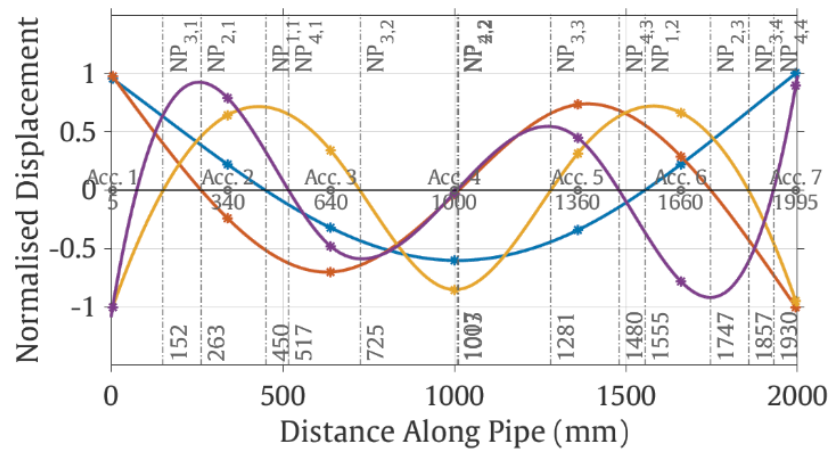

(i) Case 6c

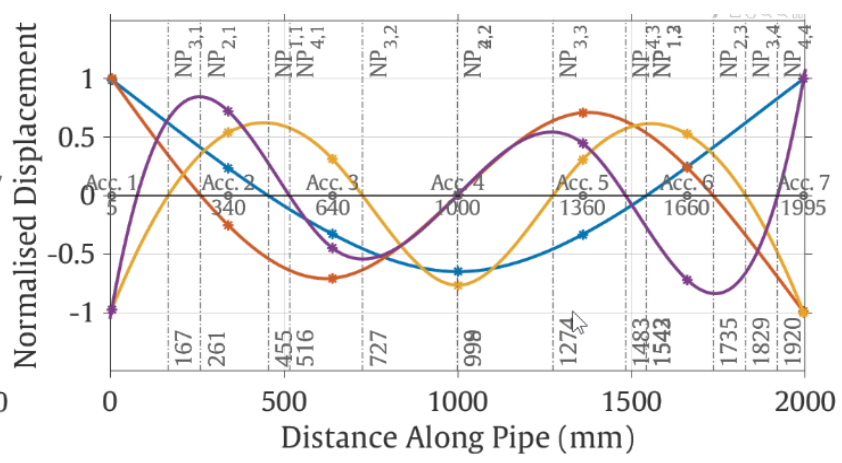

(k) Case 7c

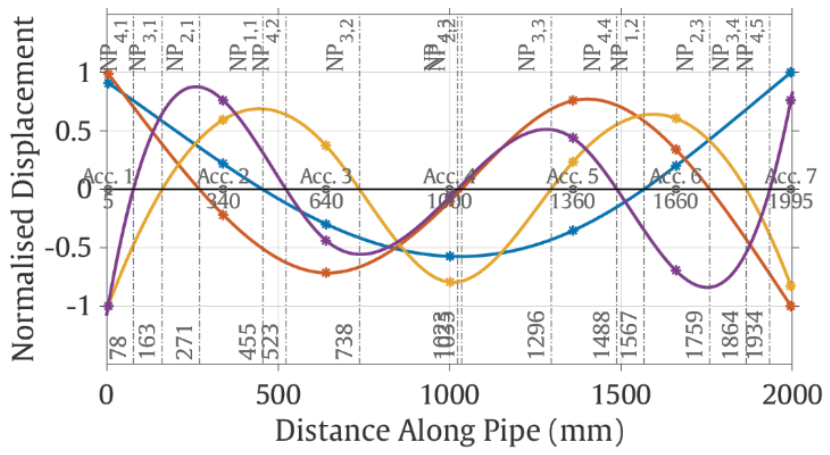

(m) Case 8c

Fig. 12 Cont $^{\prime} \mathrm{d}$

Page | 20 


\subsection{Summary of LVMP Properties}

Based on the obtained frequencies and modeshapes, the following typical LVMP properties were observed:

i) The frequency of the active part is lower than that of the passive part

ii) If the symmetry of the pipe's cross-section is perturbed by damage (as is most likely the case for local corrosion damage), the frequency of the passive local mode is approximately equal to its undamaged counterpart.

iii) Since nodal points are points of inflexion, the difference between the frequencies of the active and passive local modes is least if the damage is adjacent to a global vibration nodal point.

\subsection{Existence of LVMPS}

Following the LVMP validation criteria established in Section 2.4, LVMP existence was confirmed. Firstly, vibration peaks were validated in accordance to Eq. (1). The valid peaks for each case are highlighted in the FRFs in Fig. 11 from where both LVMP components in the non-axisymmetrically damaged cases are observable in fulfilment of criterion (i) in Section 2.4. It is also obvious that the undamaged and axisymmetrically damaged cases have only one valid peak per vibration mode. The obtained frequencies for the first four vibration modes in each case are summarised in Table 4 where the frequencies corresponding to the active and passive components are sub-scripted with ' $A$ ' and ' $P$ ' respectively.

Table 4 First four vibration mode frequencies for all test cases

\begin{tabular}{|c|c|c|c|c|c|c|c|c|c|c|c|c|}
\hline \multirow{3}{*}{$\begin{array}{l}\text { Test } \\
\text { Case }\end{array}$} & \multicolumn{3}{|c|}{ Mode 1} & \multicolumn{3}{|c|}{ Mode 2} & \multicolumn{3}{|c|}{ Mode 3} & \multicolumn{3}{|c|}{ Mode 4} \\
\hline & $\mathrm{f}_{1 \mathrm{~A}}$ & $\mathrm{f}_{1}$ & $\mathrm{f}_{1 \mathrm{P}}$ & $f_{2 A}$ & $\mathrm{f}_{2}$ & $\mathrm{f}_{2 \mathrm{P}}$ & $\mathrm{f}_{3 \mathrm{~A}}$ & $\mathrm{f}_{3}$ & $f_{3 P}$ & $\mathrm{f}_{4 \mathrm{~A}}$ & $\mathrm{f}_{4}$ & $\mathrm{f}_{4 \mathrm{P}}$ \\
\hline & $\mathrm{Hz}$ & $\mathrm{Hz}$ & $\mathrm{Hz}$ & $\mathrm{Hz}$ & $\mathrm{Hz}$ & $\mathrm{Hz}$ & $\mathrm{Hz}$ & $\mathrm{Hz}$ & $\mathrm{Hz}$ & $\mathrm{Hz}$ & $\mathrm{Hz}$ & $\mathrm{Hz}$ \\
\hline 1 & - & 152 & & - & 406 & - & - & 763 & - & - & 1202 & - \\
\hline $2 a$ & - & - & 154 & - & - & 412 & - & - & 772 & - & - & 1210 \\
\hline $2 b$ & 150 & - & - & 399 & - & 412 & 751 & - & 772 & 1184 & - & 1209 \\
\hline $2 c$ & 148 & - & - & 398 & - & - & 751 & - & - & 1185 & - & - \\
\hline 3 & - & 143 & - & - & 404 & - & - & 755 & - & - & 1186 & - \\
\hline $4 a$ & - & - & 152 & 405 & - & - & - & - & 770 & 1192 & - & - \\
\hline $4 b$ & 148 & - & 154 & 405 & - & 409 & 752 & - & 770 & 1192 & - & 1204 \\
\hline $4 c$ & 146 & - & - & - & - & 408 & 752 & - & - & - & - & 1205 \\
\hline 5 & - & 148 & - & - & 391 & - & - & 748 & - & - & 1188 & - \\
\hline $6 a$ & - & - & 151 & - & - & 407 & - & - & 767 & 1193 & - & - \\
\hline $6 b$ & 150 & - & - & 397 & - & 408 & 752 & - & 768 & 1193 & - & - \\
\hline $6 c$ & 150 & - & - & 397 & - & - & 752 & - & - & - & - & 1201 \\
\hline $7 a$ & - & - & 152 & 399 & - & - & - & - & 769 & 1159 & - & - \\
\hline $7 \mathrm{~b}$ & 141 & - & 154 & 399 & - & 410 & 729 & - & 769 & 1158 & - & 1208 \\
\hline $7 c$ & 138 & - & - & - & - & 409 & 729 & - & - & - & - & 1207 \\
\hline $8 a$ & - & - & 151 & - & - & 406 & - & - & 766 & 1132 & - & - \\
\hline $8 b$ & 149 & - & - & 379 & - & 407 & 730 & - & 766 & 1132 & - & 1193 \\
\hline $8 c$ & 148 & - & - & 379 & - & - & 730 & - & - & - & - & 1193 \\
\hline
\end{tabular}


For some of the non-axisymmetric cases ( $2 \mathrm{~b}, 6 \mathrm{~b}$ and $8 \mathrm{~b}$ ), the passive component of the first LVMP pair was less evident in the derived FRFs. For example, in Case $2 b$, the active LVMP of mode 1 was observed and validated according to Eq. (1) with a frequency of $150 \mathrm{~Hz}$ as indicated in Fig. 13. Peaks for the passive mode in the complex and imaginary FRFs were observed to be at $157 \mathrm{~Hz}$ as depicted in Fig. 13 - (a) and (c). Theoretically, the magnitude of the real FRF at the peak frequency should be zero in compliance with Eq. (1). Experimentally, an empirical threshold of 0.01 was set in order to account for the effect of noise from the signals. Based on the set threshold, the passive component of mode 1 (with a magnitude of 0.1 at peak frequency as shown in Fig. 13 - (b) appears not to meet the validation criteria. Similarly, the passive LVMPs of mode 1 in Cases $6 \mathrm{~b}$ and $8 \mathrm{~b}$ also fall short of the set threshold. Hence, for the subjected non-axisymmetric cases, only one LVMP component is validated for the given threshold. Relaxation of this threshold to say, 0.1 would have allowed both LVMP components to have been validated.

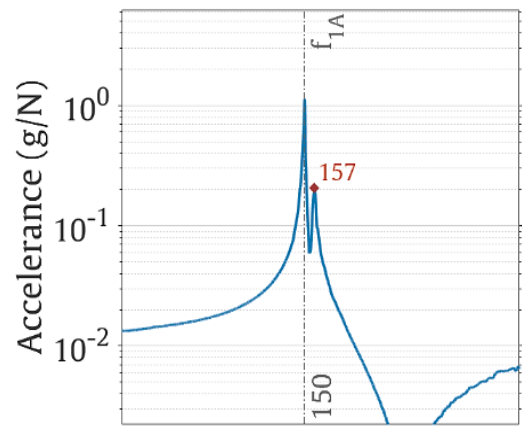

Frequency $(\mathrm{Hz})$

(a)

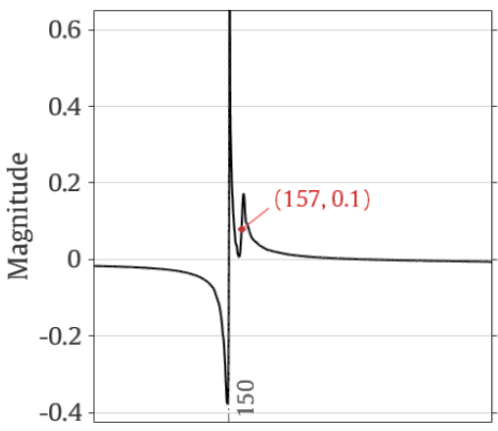

Frequency $(\mathrm{Hz})$

(b)

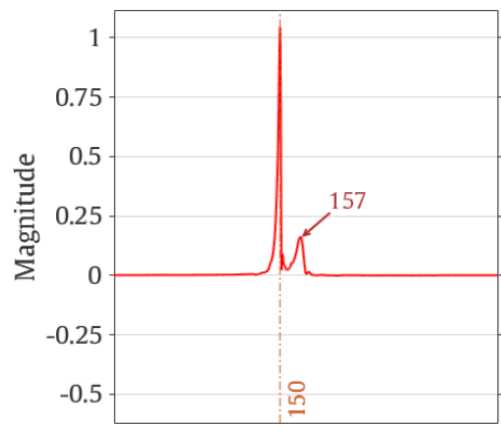

Frequency $(\mathrm{Hz})$

(c)

Fig. 13. Magnified FRFs of Case $2 \mathrm{~b}$ indicating Validation Criteria for Vibration Mode 1 in (a) Complex, (b) Real and (c) Imaginary Forms

\subsection{Modal Properties Deviation from Baseline}

\subsubsection{Baseline Frequency Deviation}

One of the important characteristics of LVMPs is that the modal features of its passive component can be representative of baseline properties. To verify this claim the deviation, $\Delta \mathrm{f}$, between the frequency of the damaged cases and their baseline counterparts per vibration mode, $\boldsymbol{i}$ was calculated according to Eq. (3).

$$
\triangle \mathbf{f}_{i}=\frac{\left|\mathbf{f}_{\text {i(damaged })}-\mathbf{f}_{\text {i(undamaged })}\right|}{\mathbf{f}_{i(\text { undamaged })}} \%
$$

The calculated values of $\Delta \mathbf{f}$ for each non-axisymmetrically damaged case are listed in Table 5 and Table 6 for passive and active LVMPs respectively and in Table 7 for the axisymmetrically damaged cases. 
Table 5 Baseline difference in Passive LVMP frequencies

\begin{tabular}{|c|c|c|c|c|}
\hline Test & $\Delta \mathbf{f}_{1 \mathrm{P}}$ & $\Delta \mathrm{f}_{2 \mathrm{P}}$ & $\Delta \mathrm{f}_{3 \mathrm{P}}$ & $\Delta \mathbf{f}_{4 \mathrm{P}}$ \\
\hline Case & $\%$ & $\%$ & $\%$ & $\%$ \\
\hline $2 a$ & 1.3 & 1.5 & 1.2 & 0.7 \\
\hline $2 b$ & - & 1.5 & 1.2 & 0.6 \\
\hline $2 c$ & - & - & - & - \\
\hline $4 a$ & 0.0 & - & 0.9 & - \\
\hline $4 b$ & 1.3 & 0.7 & 0.9 & 0.2 \\
\hline $4 c$ & - & 0.5 & - & 0.2 \\
\hline $6 a$ & 0.7 & 0.2 & 0.5 & - \\
\hline $6 b$ & - & 0.5 & 0.7 & - \\
\hline $6 c$ & - & - & - & 0.1 \\
\hline $7 a$ & 0.0 & - & 0.8 & - \\
\hline $7 b$ & 1.3 & 1.0 & 0.8 & 0.5 \\
\hline $7 c$ & - & 0.7 & - & 0.4 \\
\hline $8 a$ & 0.7 & 0.0 & 0.4 & - \\
\hline $8 b$ & - & 0.2 & 0.4 & 0.7 \\
\hline $8 c$ & - & - & - & 0.7 \\
\hline
\end{tabular}

Table 6 Baseline difference in Active LVMP frequencies

\begin{tabular}{ccccc}
\hline Test & $\Delta \mathrm{f}_{1 \mathrm{~A}}$ & $\Delta \mathrm{f}_{2 \mathrm{~A}}$ & $\Delta \mathrm{f}_{3 \mathrm{~A}}$ & $\Delta \mathrm{f}_{4 \mathrm{~A}}$ \\
Case & $\%$ & $\%$ & $\%$ & $\%$ \\
\hline 2a & - & - & - & - \\
2b & 1.3 & 1.7 & 1.6 & 1.5 \\
2c & 2.6 & 2.0 & 1.6 & 1.4 \\
4a & - & 0.2 & - & 0.8 \\
4b & 2.6 & 0.2 & 1.4 & 0.8 \\
4c & 3.9 & - & 1.4 & - \\
6a & - & - & - & 0.7 \\
6b & 1.3 & 2.2 & 1.4 & 0.7 \\
6c & 1.3 & 2.2 & 1.4 & - \\
$7 \mathrm{a}$ & - & 1.7 & - & 3.6 \\
$7 \mathrm{~b}$ & 7.2 & 1.7 & 4.5 & 3.7 \\
$7 \mathrm{c}$ & 9.2 & - & 4.5 & - \\
8a & - & - & - & 5.8 \\
8b & 2.0 & 6.7 & 4.3 & 5.8 \\
8c & 2.6 & 6.7 & 4.3 & - \\
\hline
\end{tabular}

Table 7 Baseline difference in axisymmetrically damaged frequencies

\begin{tabular}{ccccc}
\hline Test & $\Delta \mathrm{f}_{1}$ & $\Delta \mathrm{f}_{2}$ & $\Delta \mathrm{f}_{3}$ & $\Delta \mathrm{f}_{4}$ \\
Case & $\%$ & $\%$ & $\%$ & $\%$ \\
\hline 3 & 5.9 & 0.5 & 1.0 & 1.3 \\
5 & 2.6 & 3.7 & 2.0 & 1.2 \\
\hline
\end{tabular}

Page $\mid 23$ 
Based on Table 5, the maximum deviation between passive and baseline frequencies is $1.5 \%$ in vibration mode 2 of Cases $2 \mathrm{a}$ and $2 \mathrm{~b}$. This implies that passive LVMP frequencies are a good indicator of baseline frequencies to within $\pm 2 \%$ margin. Conversely, in Table 6 it can be seen that the deviation between active and baseline frequencies exceeds $9 \%$ as derived in Case 7c; therefore, baseline deviation of active LVMP frequencies can be used as a consolidating confirmation of damage existence. As for the axisymmetrically damaged cases, the maximum deviation from baseline frequencies was derived as $5.9 \%$ in Case 3, mode 1 as shown in Table 7.

It is important to note that in some of the non-axisymmetrically damaged pipes (e.g. 2, 4 and 6$)$, the baseline frequency deviation is relatively small $(<2 \%)$; nonetheless, the existence of LVMPs which are characteristic of damage, is still evident in these test cases. The observation of LVMPs (inferring damage existence) make this damage identification method stand out from traditional vibration-based methods under practical conditions, because it does not rely on the availability of the baseline data and it can detect damage even when baseline frequency shifts are small.

\subsubsection{Baseline Modeshape Deviation}

To investigate further, damaged modeshapes were compared to baseline modeshapes by computing the MAC between both sets. The results show that the minimum baseline MAC of the active component as depicted in Fig. 14 - (a) is $~ 97 \%$ (Case 8a); while the minimum baseline MAC of the passive component given in Fig. 14 - (b) is $\sim 98 \%$ corresponding to Case $8 \mathrm{c}$. This suggests that the modeshape of the passive component is more closely related to the baseline modeshape. For the axisymmetrically damaged pipes, the minimum MAC with respect to baseline was found to be $98 \%$ in Case 5 , mode 4 as shown in Fig. 15 -(b).

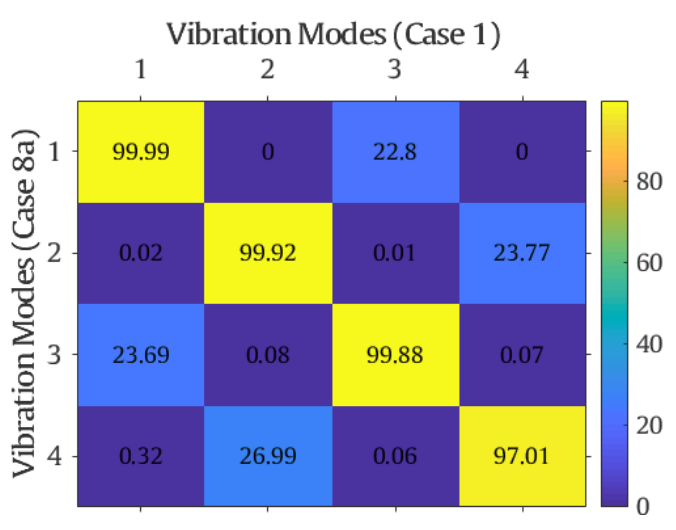

(a)

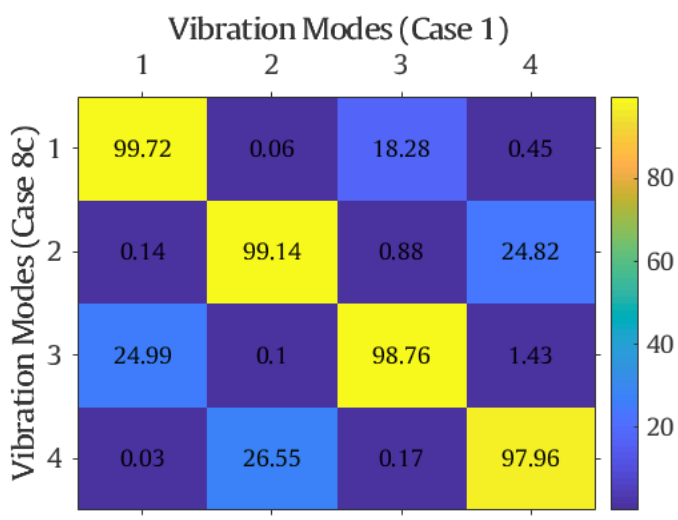

(b)

Fig. 14. Modal Assurance Criteria for non-axisymmetrically damaged cases

(a) Case 1 vs Case 8a and (b) Case 1 vs Case 8c 


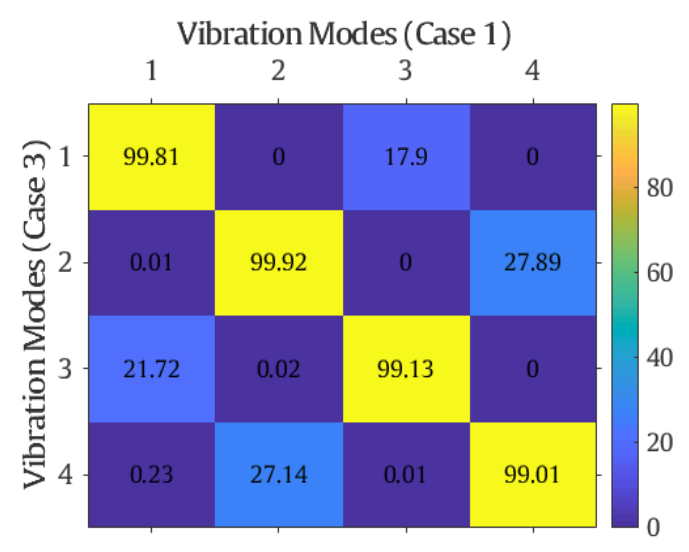

(a)

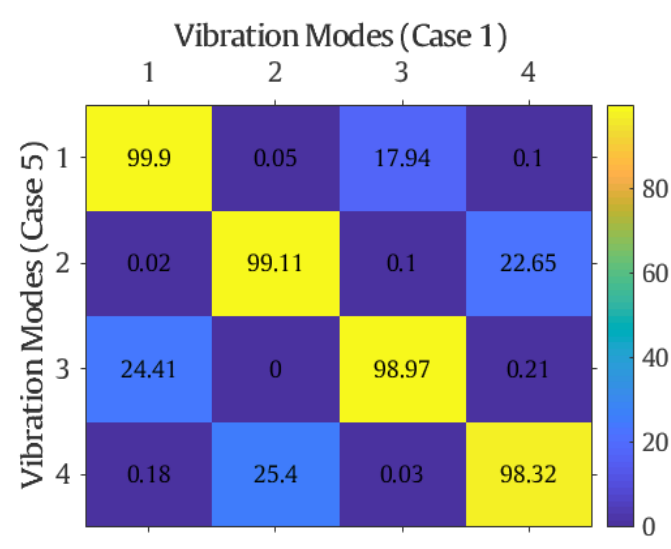

(b)

Fig. 15. Modal Assurance Criteria for axisymmetrically damaged cases (a) Case 1 vs Case 3 and (b) Case 1 vs Case 5

\subsection{Modal Properties Deviation between LVMP Components}

Having already confirmed LVMPs existence in Section 4.3 to satisfy Criterion (i) of Section 2.4, a comparison of LVMP components modal properties was done to satisfy Criteria (ii) and (iii) in the following sub-sections.

\subsubsection{LVMP Components Frequency Deviation}

The parameter $\Delta \mathrm{F}$ which represents the difference between the frequencies of the LVMP components $\left(\mathbf{f}_{A}\right.$ and $\left.\mathbf{f}_{P}\right)$ per vibration mode, $i$ was calculated for each non-axisymmetrically damaged case according to Eq. (4).

$$
\Delta \mathbf{F}_{\mathrm{i}}=\frac{\left|\mathbf{f}_{\mathrm{iA}}-\mathbf{f}_{\mathrm{iP}}\right|}{\mathbf{f}_{\mathbf{i P}}} \%
$$

In each of the non-axisymmetrically damaged pipes, the maximum and minimum frequencies from the corresponding case's sub-sets where taken as the passive and active frequencies respectively. This was done to make up for cases where only one LVMP component was captured. As an example, in Case $8 \mathrm{~b}$, mode 1 , only the active LVMP was captured (see Table 4); hence, reference was made to sub-cases ' $a$ ' and ' $c$ ' to obtain active and passive frequencies of 148 and $151 \mathrm{~Hz}$ respectively. The calculated values are given in Table 8 where the maximum difference in frequencies per LVMP is 10.4\% in Pipe 7 for vibration mode 1 . These results underpin criterion (ii) in Section 2.4 i.e. the maximum difference between LVMP frequencies is taken to be around $10 \%$ or less. 
Table 8 Frequency Deviation of LVMP Components, $\Delta \mathrm{F}$

\begin{tabular}{|c|c|c|c|c|c|}
\hline & Mode 1 & Mode 2 & Mode 3 & Mode 4 & Range \\
\hline Label & $\begin{array}{c}\Delta \mathrm{F}_{1} \\
\%\end{array}$ & $\begin{array}{c}\Delta \mathrm{F}_{2} \\
\%\end{array}$ & $\begin{array}{c}\Delta \mathrm{F}_{3} \\
\%\end{array}$ & $\begin{array}{c}\Delta \mathrm{F}_{4} \\
\%\end{array}$ & $\begin{array}{c}\mathrm{R}_{\Delta \mathrm{F}} \\
\%\end{array}$ \\
\hline 2 & 3.9 & 3.4 & 2.7 & 2.1 & 1.8 \\
\hline 4 & 5.2 & 1.0 & 2.3 & 1.1 & 4.2 \\
\hline 6 & 0.7 & 2.7 & 2.1 & 0.7 & 2.0 \\
\hline 7 & 10.4 & 2.7 & 5.2 & 4.1 & 7.7 \\
\hline 8 & 2.0 & 6.9 & 4.7 & 5.1 & 4.9 \\
\hline
\end{tabular}

\subsubsection{LVMP Components Modeshape Comparison}

The modeshapes for each LVMP pair as shown in Fig. 12 are identical, comprising of the same number of half-sine waves. As a consolidating check, the MAC between both pairs, per vibration mode was calculated and found to be nearly $100 \%$ for each vibration mode in all cases as illustrated in Fig. 16 for Case 2a vs 2c. Also, a comparison of nodal points was performed and it was found that the linear correlation (Pearson's) between LVMP component's modeshape nodal points was at least $99.9 \%$ in all cases which concurs with criterion (iii) in Section 2.4 where it is stated that the modeshapes of LVMP components are similar.

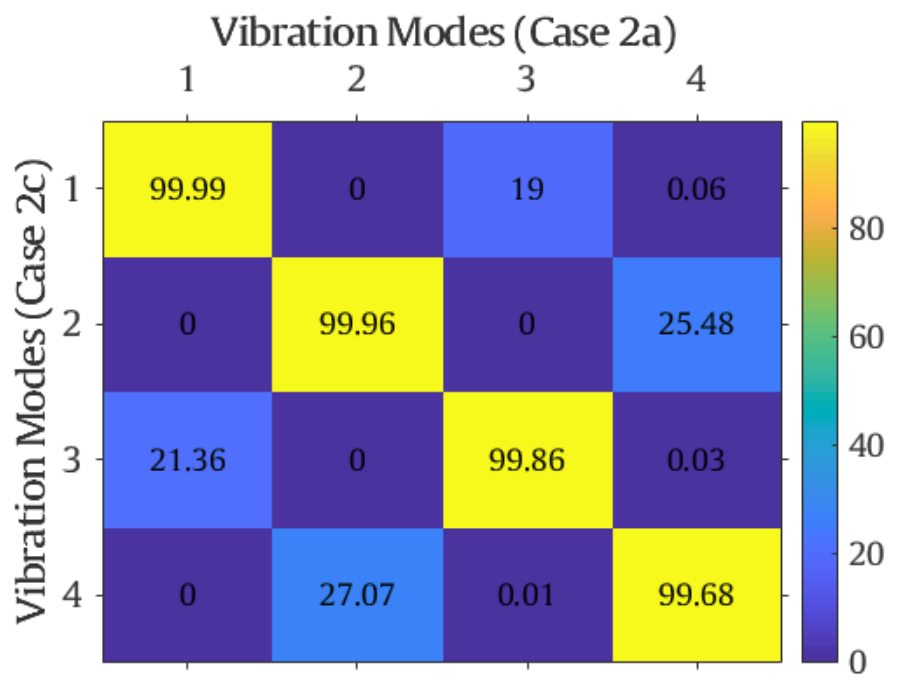

Fig. 16. An example of Modal Assurance Criteria between LVMP pairs - Case 2a vs Case 2b

\section{Proposed LVMP-based damage identification}

This section provides further details of how detection, classification, localisation and quantification of corrosion-like damage may be achieved in axisymmetric tubular structures using LVMPs. Since passive LVMP modal properties were found to be similar to 
baseline (undamaged) properties as discussed in Section 4.4, they are used in lieu of baseline properties in the damage identification process to demonstrate the baseline-free capability of the proposed method.

\subsection{Detection}

For the non-axisymmetrically damaged pipes, the mere existence of LVMPs confirms baseline-free damage detectability. For the axisymmetrically damaged pipes ( 3 and 5 ), baseline comparison is required of which the results (baseline frequency deviations) in Table 7 confirm the existence of damage (corrosion) in these cases; however, the LVMPbased damage identification process cannot be progressed beyond detection for the axisymmetrically damaged cases.

\subsection{Classification}

Having confirmed damage detectability, classification was attempted. The aim here was to blindly predict the type of damage present from modal properties of the damaged pipes. In the first instance, non-axisymmetric corrosion (in Pipes 2, 4, 6, 7 and 8) can be distinguished from axisymmetric corrosion (in Pipes 3 and 5) based on the lack of LVMPs in the test cases related to the latter. Secondly, the Range, $R_{\triangle F}$ of the LVMP component' $s$ frequency deviations as defined in Eq. (5) is calculated for each case as given in Table 8.

$$
\mathbf{R}_{\Delta \mathbf{F}}=\max \Delta \mathbf{F}-\min \Delta \mathbf{F}
$$

In Table 8, it can be seen that the minimum $\mathrm{R}_{\triangle \mathrm{F}}$ corresponds to Pipe 2 (longitudinal corrosion strip) which is expected based on the premise that the difference in LVMP frequencies of a particular mode is lowest if damage occurs at any of its nodal points as stated in Section 4.2. Therefore, it appears that the range of frequency deviations is related to the spatial characteristics of the damage. The lower the frequency range, the greater the likelihood of damage occurrence at all the nodal points of the investigated modes (i.e. virtually along the full length of the structure as in Pipe 2). Thus, spatially extensive longitudinal corrosion (such as in Pipe 2) can be differentiated from localised corrosion pits (in Pipes 4, 6, 7 and 8).

\subsection{Localisation}

Similar to classification, localisation of damage can be achieved from a vector of LVMP component's frequency deviations of the vibration modes, $\boldsymbol{i}$ with elements ranked from lowest to highest as defined by $\mathrm{K}_{\Delta \mathrm{F}}$ in Eq.(6). 


$$
\mathbf{K}_{\Delta \mathbf{F}}=[\min \Delta \mathbf{F}, \ldots, \max \Delta \mathbf{F}]
$$

The nodal points of the Passive LVMP modeshape corresponding to the lowest ranked frequency deviation provide an indication of damage location. The ranked frequency deviation vectors for Pipes 4, 6, 7 and 8 are presented in Table 9. For Pipes 4 and 7, the vibration mode with the lowest ranked frequency deviation was found to be mode 2 , whose nodal points are circa 250, 1000 and 1750mm as shown in Fig. 12 - (g) and (k) respectively. Therefore, damage could exist at either of these locations. A more accurate prediction of the damage location can be achieved by considering the second lowest frequency deviation, which corresponds to mode 4 whose nodal points are circa 100, 500, 1000,1500 and $1900 \mathrm{~mm}$. By comparison, the damage location can be narrowed down to $1000 \mathrm{~mm}$ which is the common value from both sets of nodal points. Using the same philosophy, the location of the damage in Pipes 6 and 8 can be related to nodal points of vibration mode 1 i.e. circa 450 or $1550 \mathrm{~mm}$ according to Fig. 12 - (i) and (m) respectively.

Table 9 LVMP Components Frequency Deviation Ranking

\begin{tabular}{ccccc}
\hline Pipe & \multicolumn{5}{c}{ Frequency Deviation Rank, $K_{\Delta F}$ (lowest to highest) } \\
Label & 1 & 2 & 3 & 4 \\
\hline 4 & $\Delta \mathrm{F}_{2}$ & $\Delta \mathrm{F}_{4}$ & $\Delta \mathrm{F}_{3}$ & $\Delta \mathrm{F}_{1}$ \\
6 & $\Delta \mathrm{F}_{1}$ & $\Delta \mathrm{F}_{4}$ & $\Delta \mathrm{F}_{3}$ & $\Delta \mathrm{F}_{2}$ \\
7 & $\Delta \mathrm{F}_{2}$ & $\Delta \mathrm{F}_{4}$ & $\Delta \mathrm{F}_{3}$ & $\Delta \mathrm{F}_{1}$ \\
8 & $\Delta \mathrm{F}_{1}$ & $\Delta \mathrm{F}_{3}$ & $\Delta \mathrm{F}_{4}$ & $\Delta \mathrm{F}_{2}$ \\
\hline
\end{tabular}

\subsection{Quantification}

The difference between frequencies of LVMP components is directly proportional to damage severity. A comparison was made between Pipes 4 and 7 where the damage location is the same. However, for these pipes, the percentage loss in cross-sectional area due to corrosion, $C S A_{\text {cor }}$ is 16 and $25 \%$ respectively (see Table 3 ). From Table 6 , it is evident that the frequency deviations in Cases $7 \mathrm{a}, \mathrm{b}$ and c exceeds those in Cases $4 \mathrm{a}, \mathrm{b}$ and $\mathrm{c}$ for all vibration modes implying that the damage in Pipe 7 is more severe than in Pipe 4. Similarly, a comparison Cases $6 \mathrm{a}, \mathrm{b}$ and $\mathrm{c}$ with $8 \mathrm{a}, \mathrm{b}$ and $\mathrm{c}$ confirm that Pipe 8 is more severely damaged than Pipe 6.

Interestingly, in the non-axisymmetrically damaged Pipes 7 and 8 the percentage of cross-sectional area lost to corrosion, $\mathrm{CSA}_{\text {cor }}=25 \%$ while $\mathrm{CSA}_{\text {cor }}=49 \%$ for the axisymmetrically damaged Pipes 3 and 5 (see Table 3). However, the maximum baseline frequency deviation for test cases related to Pipes 7 and 8 is $9.2 \%$ and $6.7 \%$ respectively (Table 6) which exceeds those from Pipes 3 and 5 which are 5.9\% and 3.7\% respectively (Table 7). This observation suggests that perturbation of symmetry due to damage has a 
more significant effect on modal frequencies than damage severity. Similarly, as discussed in Section 4.4.2, the minimum MAC (97\%) between baseline and the non-axisymmetrically damaged Pipe 8 is lower than the minimum baseline MAC (98\%) of the axisymmetrically damaged Pipe 5 (see Fig. 14 - (a) and Fig. 15 - (b) respectively). Therefore, it appears that the axisymmetrically damaged cases are less sensitive to damage than the nonaxisymmetrically damaged cases despite the former being more severely damaged. This confirms that symmetry perturbation results in more significant shifts in modal properties than damage severity.

\subsection{Appraisal}

Some of the limitations of the proposed concept as well as practical guidelines required to enhance a potential damage detection and identification method are listed below:

- The concept has thus far been tested only on single-location damage scenarios; thus it will be interesting to investigate how it may be applicable to pipes with multiple damage locations.

- Ideal boundary conditions (free-free) were adopted in order to explore LVMP features. Alternative boundary conditions e.g. pinned-pinned or semi-rigid connections, need further studies.

- The minimum amount of damage present for a reliable observation of LVMPs needs to determined, though under the conditions investigated herein it is as low as $4 \%$ of the structure's cross-sectional area.

- The concept has been tested with axisymmetric structures. Its applicability to other cross-sections such as doubly symmetric needs to be investigated.

- In experiments, the direction of excitation is known; however, without a priori knowledge of the damage, it is difficult to predict the vibration direction. Hence, in modal tests where the damage location is unknown and where uniaxial sensors are used for data acquisition, it is advisable to excite the test structure at more than one radial location (say 45degrees apar) so that both pairs of the LVMPs can be activated and observed in the derived FRFs.

\section{Conclusion}

The phenomenon of local vibration mode pairs in axisymmetric tubular structures has been investigated, with the underlying theory, occurrence, properties and criteria for validation of LVMPs highlighted. Experiments involving various artificial corrosion-like scenarios were performed in a laboratory setting to test the proposed LVMP-based method. In all cases, damage was successfully detected and classified. The principal conclusions are summarised below: 
- Compared with traditional vibration-based methods, the existence of LVMPs provides a promising concept for the identification of corrosion-like damage in axisymmetric tubular structures because it is based on the properties of a pair of modes, instead of baseline frequency shifts which are often smeared by measurement noise.

- LVMP properties were observed in the cases with non-axisymmetric corrosion (longitudinal strip and localised pits) and the resulting loss of symmetry was associated with more significant shifts in modal properties than damage severity.

- Passive LVMP modal frequencies are similar to baseline frequencies to a margin of within $\pm 2 \%$. Hence, baseline-free identification is possible for non-axisymmetric corrosion scenarios, which are most likely to occur in realistic field conditions.

- For localised corrosion, LVMP-based identification is possible from about $4 \%$ crosssectional area loss and above.

- The LVMP component's frequency deviation is related to the spatial characteristics of the damage. Hence, longitudinal corrosion can be distinguished from corrosion pits and the location of corrosion pits can be estimated.

- Damage severity can be linked to the difference between the frequencies of the LVMP components, which was found to be proportional to the percentage of crosssectional area lost to corrosion.

Further research in this area should seek to address the issues listed in Section 5.5 in an experimental set-up and in field applications. The test data provided in [39] may be used for facilitating the development of damage identification algorithms for this class of structures.

\section{Declaration of Competing Interest}

The authors declare that they have no known competing financial interests or personal relationships that could have appeared to influence the work reported in this paper.

\section{CRediT authorship contribution statement}

Obukho E. Esu: Conceptualization, Methodology, Investigation, Software, Formal analysis, Writing - original draft, Writing - review \& editing, Data curation, Visualization. Ying Wang: Validation, Writing - review \& editing, Resources. Marios K. Chryssanthopoulos: Supervision, Writing - review \& editing, Funding acquisition.

\section{Acknowledgment}

This research did not receive any specific grant from funding agencies in the public, commercial, or not-for-profit sectors. 
Appendix: Normalised eigenvector co-ordinates of modeshape vectors per Test Case

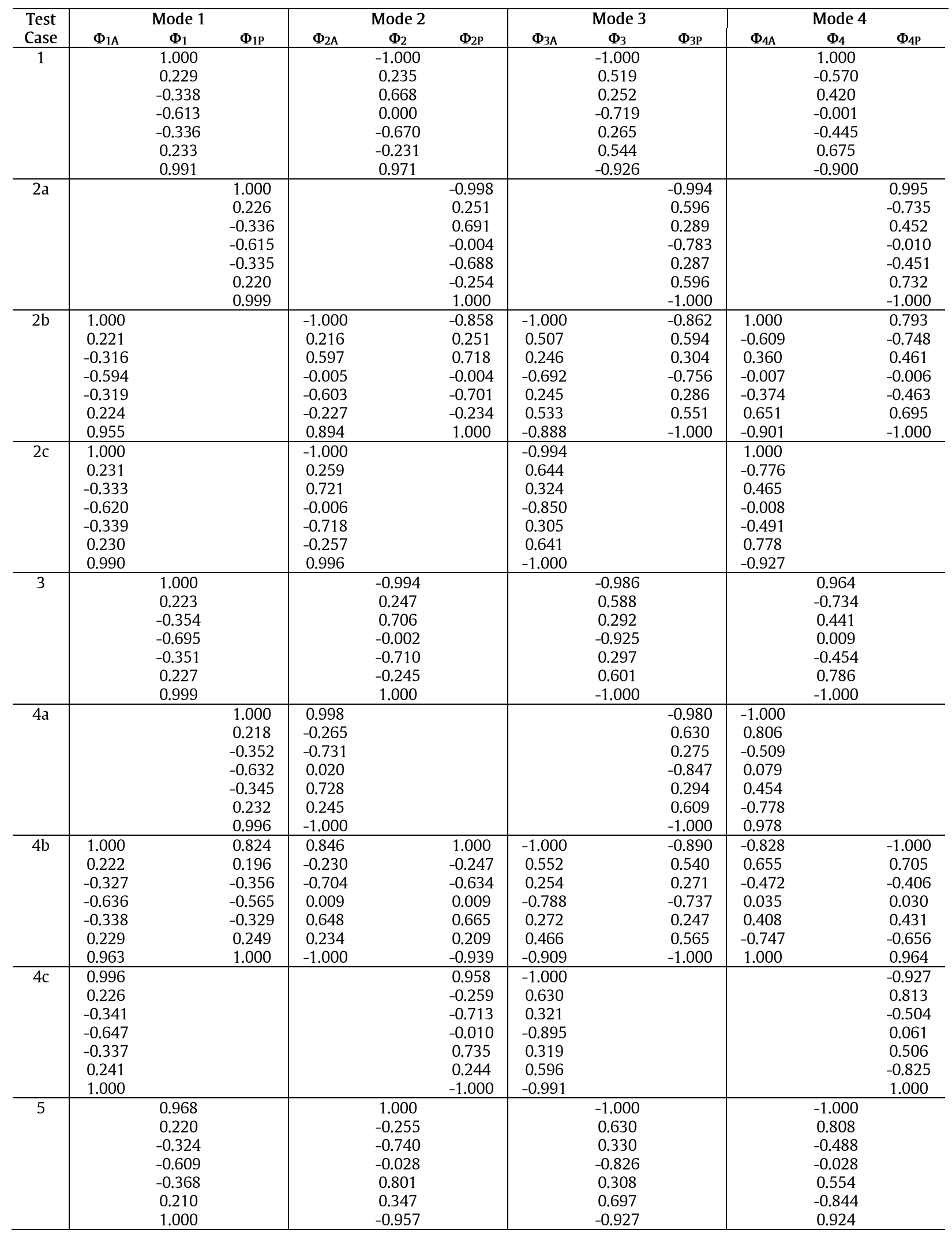




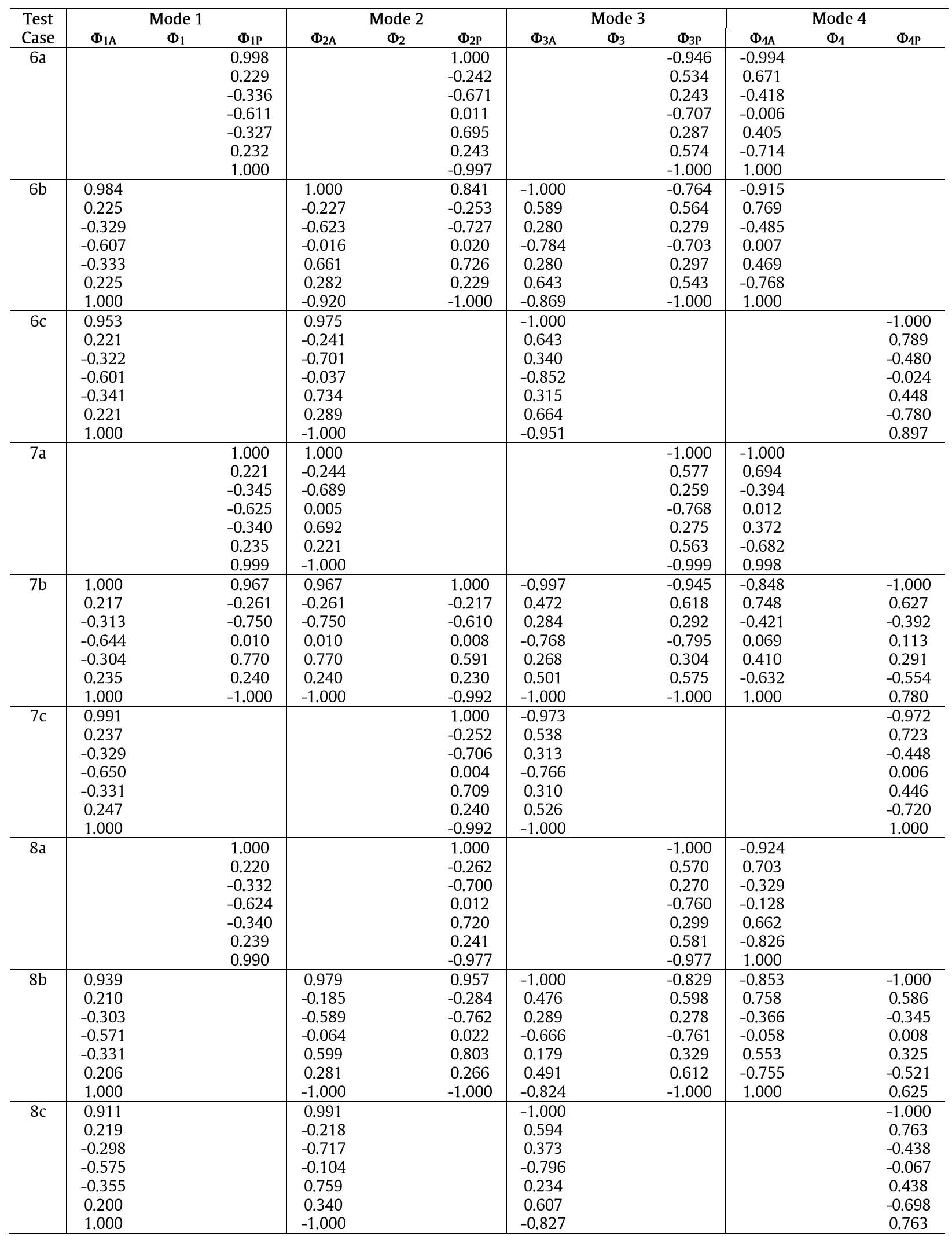




\section{References}

[1] G. Koch (2017) Trends in Oil and Gas Corrosion Research and Technologies, Production and Transmission, Ch.1, 3-30, Cost of Corrosion.

[2] P. Zoran (2016) Vojnotehni Čki Glasnik / Military Technical Courier 64(4), 1048-1064, Catastrophes Caused by Corrosion.

[3] M.J.S. Lowe, D.N. Alleyne, P. Cawley (1998) Ultrasonics, 36(1), Ultrasonics International: 147-154, Defect detection in pipes using guided waves.

[4] Q. Jiang (2010) Journal of Testing and Evaluation 38(2), ASTM International: 250-253, Study of underground oil-gas pipeline corrosion pits estimation based on MFL inspection method.

[5] X. Kong, C-S. Cai, J. Hu (2017), Applied Sciences, 7(5), The State-of-the-Art on Framework of VibrationBased Structural Damage Identification for Decision Making.

[6] Y. Wang, H. Hao (2015) Journal of Computing in Civil Engineering 29(2), Damage Identification Scheme Based on Compressive Sensing.

[7] Y. Wang, H. Hao, X. Peng X (2010) Proceedings of the Eleventh International Symposium on Structural Engineering, pp. 1375-1380, Simplified pipeline-soil interaction model for vibration-based damage detection of onshore pipelines.

[8] D.J. Ewins (2000) Modal Testing: Theory, Practice and Application. 2nd ed., Baldock, Hertfordshire, England: Wiley-Blackwell.

[9] A.K. Pandey, M.M. Samman (1991), Journal of Sound and Vibration, 145(2), 321-332, Damage detection from changes in curvature mode shapes.

[10] N. Stubbs, J.T. Kim, C.R. Farrar (1995), Proceedings of the 13th International Modal Analysis Conference, Nashville, TN, USA, 1995, pp. 210-218. Field Verification of a Nondestructive Damage Localization and Severity Estimation Algorithm.

[11] P. Cawley, R.D. Adams (1979), The Journal of Strain Analysis for Engineering Design 14(2), 49-57, The location of defects in structures from measurements of natural frequencies.

[12] M.P. Païdoussis, G.X. Li (1993), Journal of Fluids and Structures 7(2), 137-204, Pipes conveying fluid: A model dynamical problem.

[13] S.M. Murigendrappa, S.K. Maiti, H.R. Srirangarajan (2004) Journal of Sound and Vibration 270(4), 10131032, Experimental and theoretical study on crack detection in pipes filled with fluid.

[14] M. Dilena, M.F. Dell' Oste, A. Morassi (2011) Mechanical Systems and Signal Processing 25(8), 3186-3197, Detecting cracks in pipes filled with fluid from changes in natural frequencies.

[15] M.R. Naniwadekar, S.S. Naik, S.K. Maiti (2008) Mechanical Systems and Signal Processing 22(3), 693-708, On prediction of crack in different orientations in pipe using frequency based approach.

[16] H-I. Yoon, I-S. Son (2006), Journal of Sound and Vibration 292(3), 941-953, Dynamic behaviour of cracked simply supported pipe conveying fluid with moving mass.

[17] S. Mustapha, A. Braytee, L. Ye (2018), Journal of Nondestructive Evaluation, Diagnostics and Prognostics of Engineering Systems 1(2), Multisource Data Fusion for Classification of Surface Cracks in Steel Pipes.

[18] P. Razi, F. Taheri (2014), Sensors 14(9), 17174-17191, A vibration-based strategy for health monitoring of offshore pipelines' girth-welds.

[19] A. El-Sinawi, L. Al Ghailani, Y. Wang (2019), Measurement 141, 302-312, ANOVA based pipeline scale formation detection using vibration estimates and minimum number of feedback sensors.

[20] M. Saade, S. Mustapha (2020), Measurement 166, 108262, Assessment of the structural conditions in steel pipeline under various operational conditions - A machine learning approach.

[21] T. Huang, M. Chaves-Vargas, J. Yang, K. Schroder (2018) Journal of Sound and Vibration 433, 366-384, A baseline-free structural damage indicator based on node displacement of structural mode shapes.

[22] M. Dilena, A. Morassi (2002) Journal of Sound and Vibration 255(5), 915-930, Identification of crack location in vibrating beams from changes in node positions.

[23] A. Morassi (2001), Journal of Sound and Vibration 242(4), 577-596, Identification of a crack in a rod based on changes in a pair of natural frequencies.

[24] Y.Zhang, S.T. Lie, Z. Xiang, L. Qiuhai (2014), Journal of Sound and Vibration 333(6), 1671-1683, A frequency shift curve based damage detection method for cylindrical shell structures.

[25] S.A. Kudus, Y. Suzuki, M. Matsumura (2018), Jurnal Teknologi (Sciences and Engineering) 80(5), 37-44, Damage Assessment Based on Modal Analysis of Pipe Structure. 
[26] S.W. Doebling, C.R. Farrar, M.B. Prime (1998), Identification Methods," The Shock and Vibration Digest 30: 91-105, A Summary Review of Vibration-Based Damage Identification Methods.

[27] M. El-Gebeily, Y.A. Khulief (2016) Applied Mathematical Modelling 40, 5335-5348, Identification of wallthinning and cracks in pipes utilizing vibration modes and wavelets.

[28] Z. Yang, E. Oterkus (2017) Annals of Limnology and Oceanography 2(1), 001-006, Corrosion detection in pipelines based on measurement of natural frequencies.

[29] J.G. Chen, O. Büyüköztürk (2017) Journal of Sound and Vibration 408, 123-127, A symmetry measure for damage detection with mode shapes.

[30] R.N. Wake, J.S. Burgess, J.T. Evans (1998) Journal of Sound and Vibration 214(4), 761-770, Changes in the natural frequencies of repeated mode pairs induced by cracks in a vibrating ring.

[31] D. Zonta, C. Modena (2001) Journal of Sound and Vibration 241(5), 925-933, Observation on the appearance of dispersive Phenomena in damaged structures.

[32] Y.J. Yoon, J.M. Lee, S.W. Yoo, H.G. Choi (2002), Journal of Sound and Vibration, 254(4), 787-800, A method for in-plane vibration analysis of circular rings with widely distributed deviation

[33] R.N. Wake, J.T. Evans (1999), Engineering Fracture Mechanics 64(2), 177-191, The effect of cracks on the natural frequencies of axi-symmetric vibration modes of gas cylinders

[34] C.H.J. Fox, R.S. Hwang, S. McWilliam (1999), Journal of Sound and Vibration, 220(3), 517-539, The In-Plane Vibration of Thin Rings with In-Plane Profile Variations Part II: Application to Nominally Circular Rings.

[35] R.N. Wake, J.T. Evans, J.S. Burdess, H.W. Chandler (1996) Proceedings of SPIE - The International Society for Optical Engineering, pp. 311-319, Modal approach to assurance of structural integrity.

[36] D. Allaei, W. Soedel, T.Y. Yang (1986), Journal of Sound Vibration 111: 9-27, Natural frequencies and modes of rings that deviate from perfect axisymmetry.

[37] C.H.J. Fox (1990) Journal of Sound and Vibration 142(2), 227-243, A simple theory for the analysis and correction of frequency splitting in slightly imperfect rings.

[38] P. Avitabile (2018) Modal Testing: A Practitioner's Guide, John Wiley \& Sons, NY, USA.

[39] O.E. Esu, Y. Wang, M.K. Chryssanthopoulos, Vibration-Based Laboratory Test and Analysis Data from Corroded Pipe Investigation, Mendeley Data V1, (2020), doi: 10.17632/5ggw6j9hxs.1

[40] Esu O.E. An investigation of traditional vibration-based indicators and local vibration mode pairs (LVMP) for damage identification in axisymmetric tubular structures, PhD Thesis (working title, subject to change), University of Surrey, Guildford, UK (2021). Accessible via Surrey Research Insight Open Access Repository: https://epubs.surrey.ac.uk. 